\title{
INSTRUMENTOS Y PRÁCTICAS DE ENSEÑANZA DE LAS CIENCIAS FÍSICAS Y QUÍMICAS EN LA UNIVERSIDAD DE VALENCIA, DURANTE EL SIGLO XIX*
}

\author{
JOSEP SIMÓ CASTELL \\ Oxford University \\ ANTONIO GARCÍA BELMAR \\ Universidad de Alicante \\ José Ramón Bertomeu Sánchez \\ Universidad de Valencia
}

\begin{abstract}
This study is an attempt to reconstruct the evolution of spaces and scientific equipments used for the teaching of physics and chemistry in the University of Valencia in the 19th century. Through an analysis of the instruments' characteristics and their spatial distribution, the teaching programs and textbooks, as well as the profile of the target public, we try in this essay to understand the evolution of the didactic methods employed by the successive teachers and assistants when teaching physics and chemistry in the existing cabinets, amphitheatres and laboratories.
\end{abstract}

El trabajo de catalogación del patrimonio científico de la Universidad de Valencia realizado en los últimos años ha dado como resultado una colección de instrumentos de física, química y astronomía que por su número y su valor histórico y material supera con mucho las previsiones más optimistas hechas cuando este proyecto

* Este trabajo es parte del programa de investigación «Los públicos de la ciencia, la técnica y la medicina en la España contemporánea. Prácticas de enseñanza y divulgación de las ciencias experimentales (1788-1936)». financiado por el Ministerio de Ciencia y Tecnología (BHA200204611-C0302). 
se inició en $1998^{1}$. La cifra de más de mil doscientas piezas y la presencia de instrumentos que se remontan hasta las décadas finales del siglo XIX permiten apoyar esta afirmación ${ }^{2}$. Sin embargo, esta cifra y estas fechas no logran ocultar una lectura mucho menos complaciente cuando se las asocia a una Universidad que acaba de celebrar su quinto centenario y que ha albergado una intensa y continuada actividad científica durante buena parte de su historia. La colección es, desde esta otra perspectiva, el magro vestigio de un rico patrimonio hoy perdido. No es ésta una situación singular que deba explicarse recordando trágicos acontecimientos que han contribuido a la desaparición de los instrumentos. La pérdida del patrimonio histórico científico ha sido un fenómeno generalizado que ha afectado a prácticamente todas las instituciones científicas. Las razones de este hecho hay que buscarlas en el modo en que los instrumentos científicos han sido consideraros históricamente. Mucho más devastador que el fuego o las guerras ha sido la consideración de estos objetos como simples herramientas de trabajo que pierden todo su valor en el momento en que dejan de ser útiles para sus fines originales ${ }^{3}$. En los últimos años hemos asistido a un creciente interés hacia las colecciones cientificas conservadas en instituciones de investigación y enseñanza. Esto ha permitido rescatar del letargo algunos instrumentos y equipos más afortunados que han sobrevivido en las galerías de los grandes museos, en los despachos y laboratorios como objetos de decoración o simplemente olvidados en almacenes y pasillos. Su recuperación y su estudio es sin duda un primer paso para lograr que los instrumentos científicos sean considerados como parte integrante del patrimonio histórico de las instituciones y para que sea explotado el enorme potencial didáctico, histórico y museográfico que estos viejos objetos albergan.

${ }^{1}$ Sobre la colección de instrumentos científicos de la Universidad de Valencia, los autores de estre trabajo han publicado o colaborado en trabajos como J. R. BERTOMEU SANCHEZ y A. GARCIA BELMAR, "Instruments cientifics: Vells objectes per a una nova historia de la ciencia", Mètode, 25 (1999): 26-32; C. Sendra Mocholi, J. I. Catala Gorgues, A. Garcla Belmar y J. R. BERTOMEU SANCHEZ, "Los instrumentos científicos de la Universidad de Valencia: primeros resultados de un catálogo de la cultura material de la ciencia», Cronos, 4 (1-2) (2002): 29-61; J. R. Bertomeu SAnchez y A. Garcia Belmar (ed.), Abriendo las cajas negras. La Colección de Instrumentos Científicos de la Universidad de Valencia, Valencia: Universidad de Valencia, 2002.

${ }^{2}$ El catálogo completo de la colección ha sido publicado en formato CD-Rom (Abriendo las cajas negras. La Colección de Instrumentos Cientificos de la Universidad de Valencia, Valencia: Universidad de Valencia, 2002) y es consultable desde la página http://www.uv.es/=bertomeu/mate$\mathrm{rial} / \mathrm{museo} /$ instru/index.htm

3 M. BERETTA, M. «Definiendo los límites del patrimonio científico: arqueologia, historiografía y habilidades prácticas». En: J. R. BERTOMEU SANCHEZ y A. GARCIA BELMAR (Eds.), Abriendo las cajas negras. La Colección de Instrumentos Cientificos de la Universidad de Valencia, Valencia: Universidad de Valencia, 2002, págs. 83-99. 
A este renovado interés por el patrimonio histórico ha contribuido también de alguna manera la atención que los historiadores de la ciencia han comenzado a prestar en las últimas décadas a esa cultura material de la ciencia sobre la que reposa la construcción de todo discurso científico. Apoyándose sin duda en una larga tradición en la que autores como Maurice Daumas son de obligada mención ${ }^{4}$, los estudios sobre instrumentos científicos constituyen en la actualidad una especialidad bien definida de la historia de la ciencia, que cuenta con bibliografias especializadas, enciclopedias, monografías, estudios colectivos y hasta revisiones historiográficas, que permiten identificar las diferentes tendencias predominantes y los nuevos planteamientos con los que se han interrogado estas fuentes ${ }^{5}$. Aunque en mucho menor grado, los instrumentos cientificos han sido también objeto de atención por parte de quienes en los últimos años han tratado de plantear una historia de la enseñanza de las ciencias desde perspectivas que fueran más allá de las aproximaciones institucionales y sociales predominantes en este terreno, para adentrarse en los factores y mecanismos que han determinado la configuración de los discursos y los métodos de la ciencia enseñada, de un modo similar a como se ha tratado de entender la configuración de los discursos y los métodos de la ciencia surgida de la investigación ${ }^{6}$. De especial importancia en este terreno han sido los trabajos de Kathryn Olesko sobre la enseñanza de la física en los seminarios alemanes del siglo XIX?

4 Sobre los trabajos de Maurice Daumas ver A. J. TURnER, «Maurice Daumas: les instruments scientifiques", La Revue, 32 (2001), 22-32.

5 Una bibliografía sobre el tema publicada por la Scientific Instrument Commission y que se renueva periódicamente, en la página http://www.sic,iuhps.org/in bibli.htm. Para una introducción a los estudios recientes, se pueden consultar las obras colectivas de R. BUD; J. D. WARNER (eds.), Instruments of science: an historical encyclopaedia, New York: Science Museum, 1998; R. BUD; S. E. CozzeNS (eds.), Invisible Connections. Instruments, Institutions, and Science, Washington: SPIE, 1992; F.L. HOLMES, T. LEVERE (eds.), Instruments and Experimentation in the History of Chemistry, Cambridge: MIT Press, 2000; G. TURNER et al., Making instruments count: essays on historical scientific instruments presented to ..., Aldershot: Variorum, 1993; T.L. HANKINS; A. van HELDEN, “Instruments", Osiris, 9 (1994), 1-24.

6 B. BELHOSTE "Pour une réevaluation du rôle de l'enseignement dans l'histoire des mathématiques", Revue d'Histoire des Mathematiques, 4 (1998), 289-304; J.R. CHRISTIE, J.V. GOLINSKI "The spreading of the word: New directions in the historiography of chemistry, 16001800", History of Science, 20 (1982), 235-266; K.M. OLESKO "Tacit knowledge and school formation", Osiris, 8 (1993), 1-248; A. WARWCH, Marsters of theory: Cambridge and the rise of mathematical physics, Chicago: University of Chicago Press, 2003.

${ }^{7}$ K.M. OL.ESKO, Physics as a calling: Discipline and practice in the Königsbeng seminar for physics, Ithaca: Cornell University Press, 1991. En esta misma línea pueden situarse estudios como G. GOODAY, "Precision measurement and the genesis of physics teaching laboratories in Victorian Britain", British Journal for the History of Science, 23 (1990), 25-51. 
Pero, ¿qué hacer cuando las colecciones se han perdido? ¿cómo escribir una historia material de la ciencia cuando las fuentes materiales, los instrumentos y los espacios donde fueron utilizados han desaparecido?, ¡cómo reconstruir, en nuestro caso, las prácticas de investigación y de enseñanza asociadas a los instrumentos que poblaron los gabinetes y laboratorios de física y de química de nuestra Universidad cuando tales instrumentos no han llegado hasta nosotros? La desaparición de los instrumentos científicos no agota las posibilidades de una investigación que pretenda responder a estas preguntas. La adquisición, la conservación y el uso de estos objetos ha dejado un rico rastro documental que, en gran parte, se ha conservado en los archivos universitarios, en los archivos de la administración y numerosos archivos privados de los profesores que formaron parte de la Universidad, aunque esta última documentación está todavía poco explorada. Son las facturas, los registros de compra y los inventarios; los folletos de uso y catálogos de las casas comerciales; los grabados y fotografías de los instrumentos y de los gabinetes y laboratorios donde fueron usados; los planos $\mathrm{e}$ informes de arquitectos, a menudo ricos de información sobre la disposición y uso de los espacios; los manuales de enseñanza, donde son presentados los instrumentos y las experiencias con ellos realizadas; los cuadernos de clase de los alumnos y los cursos manuscritos de los profesores; las memorias y publicaciones científicas realizadas con dichos instrumentos; los libros de texto donde tales instrumentos y experimentos fueron descritos y representados; así como un largo etcétera de fuentes normativas y académicas, desde planes de estudios hasta discursos inaugurales ${ }^{8}$.

Es a través de esta rica documentación como pretendemos alcanzar el objetivo principal de este trabajo: reconstruir la evolución de los espacios y el instrumental científico destinados a la enseñanza de las ciencias físicas y químicas en la Universidad de Valencia y, a partir de un análisis de las características de tales instrumentos, su disposición espacial, los programas educativos y los libros de texto que trataron de orientar su uso y las características del público destinatario de tales enseñanzas, tratar de comprender la evolución de los métodos didácticos puestos en práctica por

${ }^{8}$ El grueso de la documentación analizada procede del Archivo Histórico de la Universidad de Valencia (AUV) y se encuentran en las cajas C. 306 (1 ), C.306 (2), C.306 (4), C.306 (9), C.292, 226 (4) y AG-C.1178. Aprovechamos esta nota para agradecer la ayuda prestada por parte de las personas responsables del archivo. 
los sucesivos responsables de la enseñanza de estas materias a lo largo del siglo XIX .

\section{Demostrar y repetir}

Puede que resulte difícil y probablemente inútil tratar de fijar un origen preciso desde el que iniciar la historia de la colección de instrumentos científicos de una universidad como la de Valencia, con más de cinco siglos de historia. La formación de una colección de estas características hay que entenderla como un proceso de largo recorrido en el que los objetos fueron adquiriendo y modificando su forma y significado en estrecha interacción tanto con los espacios en los se usaron como con las prácticas de investigación y enseñanza en las que se integraron. Esto no significa, sin embargo, que no se puedan identificar ciertos momentos en los que la colección se organizó y adoptó formas que la entroncan de manera más o menos directa con su historia más reciente. Así, podríamos señalar el proyecto de organización del Laboratorio químico y del Aula de fisica experimental y mecánica a finales del siglo XVIII como un momento crucial en la organización de unos espacios y un instrumental en los que se reconocen algunos de los elementos distintivos de la colección en el siglo XIX ${ }^{10}$.

Las funciones que tanto el laboratorio de química como el aula de física experimental y mecánica debían cumplir quedaban recogidas en el texto del Plan de estudios elaborado por el Rector Vicente Blasco en $1786^{11}$. Por lo que se

${ }^{9}$ Los supuestos y objetivos de este trabajo de investigación sobras las prácticas de enseñanza de las ciencias han sido expuestos en A. GARCIA BELMAR; J.R. BERTOMEU SANCHEZ, "Motivi, fonti e domande per una storia dei contenuti e delle pratiche dell' Insegnamento della chimica" En F. ABBRI; M. CIARDI, Storia e Fondamenti della Chimica, Rendiconti della Accademia nazionale delle scienze detta dei, 1999, 3-22.

${ }^{10} \mathrm{~L}$ a organización y el funcionamiento de la cátedra de química y el laboratorio, así como del aula de física experimental y mecánica surgidos del Plan Blasco de 1786 ha sido estudiada en R. GAGO et al., "El plan del rector Blasco (1786) y la renovación e las disciplinas cientificas en la Universidad de Valencia: la química y la enseñanza clínica”, Estudis, 6 (1977), 157-170; A. TEN, "Un intento de renovación científica en la Universidad del siglo XVIII. La cátedra de química de la Universidad de Valencia», Llull, 5 (1983), 133-147; A. TEN, "La ciencia experimental en la Universidad espafiola de la Ilustración. El laboratorio químico de la Universidad de Valencia: 1787-1807", Asclepio, 28 (1985), 287-301 y A. GARCIA; J.R. BERTOMEU, «El laboratorio químico de la Universidad de Valencia a través de sus gastos". En: H. CAPEL; J.M. LOPEZ PINERO; J. PARDO (coord.), Ciencia e Ideologia en la ciudad, I Coloquio Interdepartamental, Valencia: Generalitat Valenciana, 1992, t. I, 123-132.

${ }_{11}$ Plan de Estudios aprobado por S. M. Y mandado observar en la Universidad de Valencia, Valencia: Imp. De Benito Monfort, 1787. 
refiere al funcionamiento del aula de física y mecánica, el Plan indicaba que, además de las lecciones teóricas de "Estática, Dinámica, Hidrostática, Hidrodinámica, Óptica, Catóptrica, Dióptrica, Perspectiva", el catedrático encargado del curso debía dedicar una segunda hora a "explicar las máquinas" y a realizar los "experimentos convenientes para dar a conocer las propiedades de los cuerpos sólidos y fluidos, especialmente del aire, del agua, del fuego y de la luz". Para ellos se recomendaba el uso del "Exâmen marítimo de D. Jorge Juan, y las Lecciones de Óptica del Abate La Caillen. Para la organización del gabinete de física y la ejecución de las demostraciones, el Plan Blasco preveía también la dotación de una plaza de "Maquinista", entre cuyas obligaciones se encontraba la de "mantener limpias y en buen estado las máquinas y manejarlas á la orden de los Catedráticos de Mecánica y Astronomía». Para cumplir con tales funciones el Plan señalaba que el «sujeto que se elija para este empleo deberá ser notoriamente hábil en la composición y manejo de las máquinas". Tales capacidades debieron ser las que los responsables de la universidad vieron en José Pérez, artesano valenciano que había construido un Globo Celeste para la Universidad, en 1787, un año antes de lograr su puesto junto al entonces catedrático de física Pedro Morata y Meliá (1760-1803).

Fue el propio José Pérez el responsable de la construcción de las máquinas que desde los primeros momentos permitieron realizar con cierta asiduidad las lecciones prácticas de física y mecánica. A él se deben, entre otros, una de las primeras bombas neumáticas y campanas con las que se realizaron las experiencias de vacío, o la máquina eléctrica con la que se llegaron a realizar experiencias médicas ${ }^{12}$. Pérez se basó en los diseños que podían encontrarse en los principales tratados de física experimental del abate Nollet (1700-1770), Pieter van Musschenbroek (1692-1761) o William Jacob's Gravesande (1688$1742)^{13}$. El gabinete incrementó de forma considerable sus fondos gracias a la adquisición de dos colecciones privadas: la de Joachin Fos y la de Antonio

${ }^{12}$ A. TEN, "La física experimental en la universidad española de fines del siglo XVIII y principios del XIX. La Universidad de Valencia y su aula de mecánica y física experimental", Llull, 6 (1983), 165-189.

${ }^{13}$ Una situación parecida es la descrita por Carles Puig-Pla para instituciones como la Junta de Comercio o la Academia de Ciencias Naturales y Artes de Barcelona a finales del siglo XVIII (PUIG-PLA, C., "Desarrollo y difusión de la construcción de máquinas e instrumentos científicos: el caso de Barcelona en los siglos XVIII y XIX Ciencias Sociales, 69 (8) (www.ub.es/geocrit/nova.htm). 
Castellví, Conde de Carlet, que la Universidad compró a la muerte de éstos. Durante mucho tiempo la custodia de los instrumentos, así como la organización y ejecución de las sesiones prácticas corrió a cargo del maquinista Pérez, quien debía transportar desde su casa las máquinas que precisaba para las experiencias programadas. Poco después de la incorporación de Antonio Galiana (1762-1840) al frente de la cátedra se renovaron las instalaciones del aula, dotándola de estantes y armarios donde colocar la colección a la vista de los alumnos ${ }^{14}$.

Aunque una parte de este primer material se perdió durante los bombardeos que el edificio de la Universidad sufrió durante la invasión de las tropas napoleónicas, otros sobrevivieron estableciendo un hilo de continuidad con el gabinete de física reorganizado décadas más tarde. Podemos conocer la composición que este gabinete llegó a alcanzar en las primeras décadas del siglo XIX a través de los inventarios realizados entre 1846 y 1847 dentro del plan de renovación del material cientifico de las recién creadas Facultades de Filosoffa. Ramón Teruel, por entonces catedrático de astronomía, fue el encargado de esta tarea, y a él se deben los varios inventarios que registraron y organizaron según diferentes criterios los ciento doce «instrumentos, maquinas y demás objetos que forman el Gabinete de Física de la Universidad de Valencian" ${ }^{15}$. Siguiendo el inventario que presentaba los instrumentos agrupados en secciones temáticas, encontramos en primer lugar los siete instrumentos de «mecánica», encabezados por una máquina de Atwood "para demostrar las leyes de la gravedad" y otra "de las fuerzas centrales", acompañada de "cuatro aparatitos destinados a manifestar las leyes de las fuerzas centrípeta centrifugan. Al igual que en los manuales de física, a esta primera sección seguían las de hidráulica y pneumática. Entre los trece objetos de hidráulica se encontraba un modelo de bomba doble "de las que sirven para apagar incendios", varios densímetros, balanzas hidrostáticas y analíticas, y un grupo de tubos y recipientes para demostrar la presión y resistencia de los líquidos. Una gran máquina pneumática de dos cuerpos según el modelo de Babinet era el núcleo de la decena larga de objetos de pneumática, entre los que figuraban varias bombas de un solo cuerpo con sus correspondientes accesorios, asl como dos "fuentes de compresión" y una selección de accesorios para demostrar las propiedades físicas del aire y del vacío.

${ }^{14}$ TEN, "La física experimental..." op. cit. Págs. 173-178.

${ }^{15}$ AUV, Fac. de Ciencias C. 306 (1). 
Seguian a continuación las cuatro secciones correspondientes a los fluidos imponderables: calor, luz, electricidad y magnetismo. La primera, llamada de «termología», reunía varios juegos de espejos metálicos para el estudio del calor radiante, un calorímetro de Lavoisier, varios tipos termómetros y una eolipila. Igualmente heterogéneo era el grupo de veinte objetos de óptica, en el que junto a varios tipos de lentes, prismas y espejos, se encontraban tres tipos de microscopios - simple, compuesto y solar-, y dos telescopios, uno grande catadióptrico y otro de menor tamaño con dos oculares. La gran máquina eléctrica era el núcleo de la colección de objetos de electricidad, formada por unos veinte accesorios, entre los que destacaban las pilas de Volta, electroforos, electroscopios y un "taburete de nogal con sus pies de cristal". Cerraban este bloque un grupo de imanes, agujas magnéticas y un galvanómetro dentro de la sección "magnética" y dos aparatos electromagnéticos (de Pouillet y de Clarke), en la "electromagnética". Para el estudio de la "acústica" se contaba con un "órgano de madera" sobre el que se intercambiaban toda una colección de flautas, tubos, membranas, láminas y varillas que permitían demostrar los fenómenos de producción y propagación del sonido. Varias esferas terrestres y celestes, un higrómetro de Saussure y un grafómetro formaban la sección de meteorología y la geografía con la que se cerraba el inventario.

Desconocemos cómo fueron adquiridos cada uno de estos objetos, aunque muy probablemente fue el resultado combinado de encargos hechos a artesanos locales, capaces de reproducir los modelos ilustrados en los libros de física, con compras a los fabricantes que durante este primer tercio del siglo XIX comenzaban a difundir sus catálogos y sus productos a través de las instituciones educativas europeas deseosas de reunir en sus gabinetes colecciones lo más completas posible ${ }^{16}$. Lo cierto es que esta primera experiencia de introducción de la enseñanza de la física experimental en la Universidad de Valencia dio como resultado un gabinete de física que llegó a contar con un material mínimo y rudimentario en su mayor parte, pero suficiente para demostrar los fenómenos y leyes de la física, tal y como ésta era delimitada y ordenada en los manuales de la época. En esta primera colección

${ }^{16}$ P. BrenNI, "La industria de la precisión en el siglo XIX". En: A. GarCla; J.R. BertomeU (ed.), Abriendo las cajas negras..., op. cit., págs. 53-73; P. BRENNI, "La funzione degli instrumenti scientifici nella didattica fra Settecento e Ottocenton, Studi Settecenteschi, 18 (1998), 421-431. 
formada durante las últimas décadas del siglo XVIII y las primeras del XIX, podemos encontrar algunos de los instrumentos didácticos más representativos de los gabinetes de física de la época ${ }^{17}$. Se trata en muchas ocasiones de versiones más o menos modificadas de instrumentos que fueron clave en investigaciones y polémicas científicas en el pasado. Una de las áreas importantes de este corpus teórico y práctico es la mecánica. Aunque no se trate precisamente de la disciplina más novedosa durante los siglos XVIII y XIX, contribuyó decisivamente a la difusión de la nueva filosofía natural. La mecánica fue en gran medida protagonista de un nuevo estilo de práctica científica a través de las demostraciones experimentales, influyendo fuertemente en la configuración de los programas de enseñanza de la física. Muchas de las demostraciones experimentales e instrumentos introducidos o desarrollados por Desaguliers, 'sGravesande, Musschenbroek o posteriormente Nollet, todavía hoy sobreviven en la enseñanza. El aparato diseñado por 'sGravesande para ilustrar la trayectoria parabólica recorrida por un objeto lanzado con cierta velocidad no añadía un mayor conocimiento a las teorías del movimiento. Sin embargo, mediante aros colocados con exactitud sobre un panel, a continuación de la rampa sobre la que se soltaba el objeto, mostraba claramente la trayectoria del móvil y la fijaba en la mente del público observador. El doble cono de Desaguliers, a través de una disposición sencilla - un doble cono sobre una rampa formada por dos varas de maderamostraba el papel del centro de gravedad en el movimiento de los cuerpos, frente a la perplejidad del observador que veía como el objeto ascendía por la rampa, contrariamente a lo esperado sin haber reflexionado sobre la disposición del montaje ${ }^{18}$. Otros instrumentos y demostraciones experimentales intervinieron más directamente en las polémicas científicas que desembocaron en la física del siglo XIX. Un ejemplo paradigmático es el de la bomba de vacío, que fue el centro de los experimentos, discusiones y escritos de importantes filósofos naturales durante el siglo XVII enfrascados en el estudio de las propiedades físicas del aire y en las polémicas acerca de la

17 G. SUTTON, Science for a Polite Society. Gender, Culture and the Demonstration of Enlightenment, Boulder: Westview Press, 1995 ; A.Q. MORTON; J.A. Wess, Public and private science. The king George III collection, Oxford: Oxford University Press, 1993; V. GUIJARRO MORA, Los Instrumentos de la Ciencia Ilustrada. Fisica experimental en los Reales Estudios de San Isidro de Madrid (1770-1835), Madrid: UNED, 2002.

18 G. SuTton, Science for a Polite Society. Gender, Culture and the demonstration of Enlightenment, Boulder: Westview Press, 1995; T. L. HaNkINS, Science and the Enlightenment, Cambridge: Cambridge University Press, 1985. 
existencia del vacío y del comportamiento de los cuerpos y seres vivos inmersos en él' ${ }^{19}$.

En otras ocasiones fueron instrumentos ideados por artesanos $\mathrm{e}$ industriales con fines aplicados, que pasaron posteriormente a integrarse en las colecciones de enseñanza. Es el caso del pirómetro de Wedgwood, diseñado por Josiah Wedgwood a mediados del siglo XVIII, en el ámbito de la fabricación de la cerámica, y pasando más tarde a formar parte de los instrumentos incluidos habitualmente en los gabinetes de física para el estudio del calor. Finalmente, podemos también encontrar versiones modificadas y perfeccionadas de instrumentos que fueron ideados y evolucionaron en el ámbito de la propia enseñanza de la física. Este es el caso, por ejemplo, de la máquina de Atwood ideada a finales del siglo XVIII como instrumento didáctico para demostrar las leyes que rigen el movimiento de caída de los cuerpos ${ }^{20}$.

Sea cual fuere su origen, estas máquinas y aparatos de física pasaron a engrosar a lo largo del siglo XVIII los gabinetes de física creados en toda Europa, formando colecciones cuyos catálogos fueron asemejándose cada vez más a la lista de fenómenos y principios contenidos en los principales tratados de física. En su ordenación, su composición y hasta en su forma aquellas colecciones de máquinas reproducían los capítulos y las ilustraciones de los principales libros de fisica. Editores y fabricantes de instrumentos contribuyeron de forma decisiva a establecer esta vinculación unívoca entre el contenido de los libros de texto y de los catálogos de fabricantes con el de los gabinetes de física que las instituciones educativas se afanaban en completar. Este arsenal didáctico puesto al servicio de los profesores de física ayudó también de forma decisiva a consolidar un modelo de enseñaza que fue, hasta bien entrado el siglo XIX, el principal y a menudo único método didáctico empleado en la enseñanza de las ciencias. Nos referimos a los cursos magistrales acompañados de demostraciones experimentales. En ellos, las lecciones dictadas por los profesores eran ilustradas con la descripción de experiencias ejecutadas e instrumentos manipulados por el propio profesor 0 ,

19 Sobre las experiencias con la bomba de vacío, ver el ya clásico estudio de S. SHAPIN, S. SCHAFFER, Leviathan and the air-pump: Hobbes, Boyle and the experimental life, Princeton: Princeton university press, 1985.

${ }^{20}$ S. SCHAFFER, "Machine Philosophy: Demonstration Devices in Georgian Mechanics", Osiris, 9 (1994), 157-182. 
más generalmente, por sus ayudantes y preparadores. Se trataba por lo general de experiencias didácticas destinadas a confirmar el cumplimiento de las leyes o fenómenos enunciados previamente por el profesor. A los alumnos quedaba reservada únicamente la posibilidad de observar las experiencias mostradas frente a ellos ${ }^{21}$.

Es en este contexto en el que podemos interpretar el significado de las abundantes referencias encontradas en los inventarios realizados por Teruel acerca del uso al que cada una de estas máquinas estaba destinado. Estos documentos nos presentan máquinas y aparatos ligados de forma unívoca a la demostración ante los alumnos de un determinado fenómeno físico, un determinado comportamiento o propiedad física de los cuerpos o el cumplimiento de una determinada ley física. El «aparato del Haldat" servía "para probar que la presión de los líquidos es siempre como la base multiplicada por la altura", mientras que la máquina eléctrica y sus accesorios deberían servir "para demostrar las corrientes eléctricas, las atracciones y repulsiones y la producción de chispas y penachos". Hasta los accesorios que acompañaban a las grandes máquinas tenían usos bien definidos y predeterminados: las dos flautas cúbicas del órgano servían para "demostrar que el numero de vibraciones está en razón inversa de sus dimensiones homólogas», mientras que las cuatro rectangulares eran "para demostrar que el sonido es siempre igual cuando el producto de la altura por la profundidad es el mismo». Por sencillos que fuesen los objetos, cada uno tenía asignado un preciso y único fin. El «balón de cristal con llave" era "para demostrar el peso de los gases", mientras que el "vaso cónico" permitía "demostrar la presión de los gases de bajo arriba" y un

${ }^{21}$ Sobre la demostración experimental en el contexto de la enseñanza de las ciencias físicas y químicas, véase, además del trabajo ya citado de G. Sutton, el volumen especial "Science Lecturing in the $18^{\text {th }}$ century", British Journal for the History of Science, 28 (1), (1995) o los trabajos de S. Pumfrey, "Who did the work? Experimental philosophers and public demonstrators in Augustan England", British Journal for the History of Science, 28 (1995), 131 56; A.Q. MORTON, "Lectures on natural philosophy in London, 1750-1765" British Journal for the History of Science, 23 (1990), 411-434; J. MERTENS, "Shocks and Sparks: The voltaic pile as a demonstrative devicen, Isis, 89 (2) (1998), 300-311. T.L. HaNKINS, J.S. ROBERT, Instruments and the imagination, Princeton: Princeton University Press (especialmente el capitulo "The magic lantern and the art of demonstration"); J. N. HaYs, "The London lecturing empire, 1800-50w. En: Ian INKSTER, Jack MORRELL., Metropolis and province: Science in British culture, 1780-1850, London: Hutchinson, 1983; I. IKSTER, "The public lecture, an instrument of science education for adults - the case of Great Britain c. 1750-1850 ${ }_{\text {Pedagogica }}$ Historica, XX, 1, 80-107. 
"hexágono de hoja de lata con caras pintadas" debía servir "para demostrar el poder emisivo del calórico". Un lacónico "para sus experimentos propios" sentenciaba el uso predestinado para el "termoscopio de Rumford». Cada instrumento encarnaba así el principio o fenómeno que debía demostrar, hasta confundirse con él. La reproducción del fenómeno era imposible sin la participación del instrumento y cada instrumento estaba diseñado para permitir la reproducción de un determinado fenómeno. Las dos actividades atribuidas en el Plan del rector Blasco a los cursos de física, "explicar las máquinas» $\mathrm{y}$ "dar a conocer las propiedades de los cuerpos», aparecen así reducidas a un solo acto: la máquina representa al fenómeno físico y la descripción de su funcionamiento es la demostración del fenómeno en cuestión.

Aunque éste fue también el fundamento de los métodos didácticos empleados en la enseñanza de la química, la documentación y los propios utensilios del laboratorio de química nos desvelan importantes diferencias. Para la enseñanza de la química, el Plan Blasco preveía también la doble secuencia de clases teóricas matinales por parte del catedrático y de clases vespertinas dedicadas a demostrar las operaciones correspondientes a la clase del día, a cargo del propio catedrático con la ayuda de su demostrador:

El catedrático de química tendrá lectura en el laboratorio químico. Por la mañana ocupará hora y media enseñando la química en general, y sus aplicaciones a las artes, fábricas y minas, por las Instituciones de Baumé, que por ahora han de estudiar en dos años los que concurran a esta clase. Por la tarde ocupará otra hora y media enseñando los elementos de Macquer, y aplicándolos solamente a la parte médica de la química. A esta podrán también concurrir cualesquiera otras personas. Tanto por la mańana como por la tarde se harán las operaciones correspondientes a la lección del día...

Pero, a diferencia de lo indicado en las clases de física, el Plan añadía para las de química una frase clave para entender el diferente planteamiento didáctico desde el que se ponía en marcha la enseñanza de cada una de estas dos ciencias experimentales. En el caso de la química, el Plan del rector Blasco indicaba que en las clases vespertinas destinadas a demostrar las operaciones correspondientes 
a la lección del día "cuidará el Catedrático que sus discípulos aprendan a hacerlas, y que algunas veces las haganm. Las experiencias debían realizarse de tal modo que los alumnos no sólo entendieran cómo se hacían, sino que fuesen capaces de repetirlas. ¿Qué tipo de demostraciones y con qué tipo de instrumentos podían plantearse estos experimentos de modo que los alumnos pudieran reproducirlos por sí mismos? ¿Qué objetivos didácticos se perseguían con esta voluntad de permitir a los asistentes a los cursos la reproducción de los experimentos?

El laboratorio proyectado en el Plan del rector Blasco nunca llegó a realizarse y en su lugar funcionó un "laboratorio interino" que fue equipado con lo imprescindible para realizar las demostraciones de las experiencias explicadas en clase. Tomás Manuel de Villanova Muñoz y Poyanos (17371802), titular de la cátedra de química desde 1788 , señalaba en un informe sobre la construcción del laboratorio interino que la dotación de unas instalaciones de estas características, concebidas especialmente para las "operaciones Químico-Farmacéuticas», no requería «mayor aparato y número de instrumentos que los que se necesitan para un obrador de boticarion" ${ }^{22}$. Villanova imaginaba un laboratorio formado por "dos piezas proporcionadas, la una rodeada de bancos para las lecciones, y la otra con cocina a un cabo para las operaciones, y además algunos pequeños cuartos para el carbón y otras provisiones"; todo ello dotado de las instalaciones básicas de agua, de una chimenea para albergar los diferentes tipos de hornos y de una "mesa bastante capaz para las operaciones en fríon. Estos espacios e instalaciones básicas se asemejaban en lo esencial a las que podín encontrarse a finales del siglo XVIII en otras muchas instituciones de enseñanza de la química europeas. El aula para las lecciones, a menudo un viejo teatro anatómico reacondicionado con hornos y conducciones de humo y agua para albergar los cursos de química, era el centro de toda la actividad. En ella los alumnos se disponían en bancos o gradas alrededor de una gran mesa central en el que el profesor dictaba las lecciones y realizaba con la ayuda de su preparador las operaciones químicas correspondientes. Aneja a ella, una segunda sala donde profesores y preparadores ponían a punto las experiencias que posteriormente eran

22 Informe de Tomas de Villanova al regidor comisario de universidad Ollet, sobre construcción de un laboratorio interino, Valencia, 2 de mayo de 1788 (Citado en TEN, "La ciencia experimental...", op. cit., pág. 310). 
demostradas en el aula principal. Separados de ellas, los almacenes de reactivos y en ocasiones de instrumentos y utensilios químicos ${ }^{23}$.

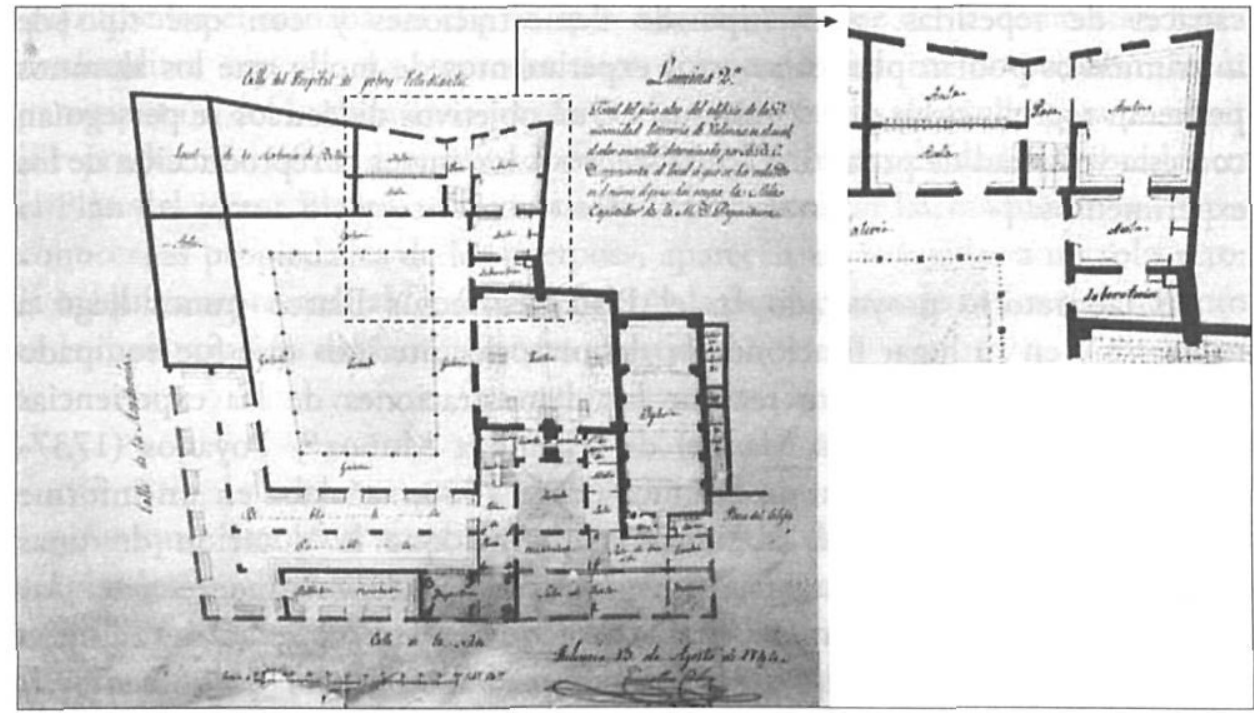

Figura 1.

Plano de la primera planta del edificio de la Universidad de Valencia, diseñado por Timoteo Calvo, en 1844 (Archivo de la Catedral de Valencia, Sig. H. 15.3. Pergamino nº 9602)

No disponemos hasta el momento de fuentes que nos hayan podido desvelar en qué medida este laboratorio imaginado por Villanova fue hecho realidad, aunque todo parece indicar que la situación de los locales dedicados a la química distó mucho de este proyecto ideal. Los planos del edificio de la Universidad

${ }^{23}$ Ver, entre otros, los trabajos recogidos en C. MeINEL, "Chemische Laboratorien: Funktion und Disposition", Berichte zur Wissenschaftsgeschichte, 23 (2000), 287-302 o el capítulo dedicado a los espacios de enseñanza en T. A. MARKUS, Buildings and power: Freedom and control in the origin of modern building types, London: Routledge, 1993. La relación entre el diseño de los espacios y la producción de conocimientos ha generado una amplia literatura recogida en parte en trabajos como los de A. OphiR, S. Shapin, S. Schaffer, (ed.), "The place of knowledge: the spatial setting and its relation to the production of knowledge", Science in context, 4 (1991); S. SHAPIN, "The house of experiment in $17^{\text {th }}$ century England", Isis, 79 (1988), 395. J. GOLINSKI, "The place of production", En: Making natural knowledge. Constructivism and the history of science. Cambridge, Cambridge University Press, 1998, 79-103. 
de Valencia diseñados en 1844 por Timoteo Calvo muestran un pequeño laboratorio comunicado con una gran aula rodeada de armarios, posiblemente destinados a albergar la colección de instrumentos de química y máquinas de física (Figura 1). Los espacios solicitados por Villanova volvieron a reclamarse en 1846, reproduciendo casi de forma literal el diseño imaginado por él. En su "Descripción del local que necesita la cátedra de química", el entonces titular de la cátedra José Montserrat y Ruitort consideraba imprescindible contar con «una sala de explicación en forma de anfiteatro con mostrador, cubas neumáticas de agua y de mercurio, banco y chimenea, dos armarios para reactivos y una pizarra móvil». Junto a esta estancia principal, se consideraba necesario contar con una "sala de descanso con surtidor a la de la clase", una "sala gabinete con armarios para guardar las máquinas y demás medios de enseñanzan, un «laboratorio con los aparatos" y finalmente un "patio o deslunado para algunas operaciones", posiblemente aquéllas que fueran acompañadas por el desprendimiento de gases tóxicos o pestilentes ${ }^{24}$. Como veremos más adelante, este diseńo de espacios logró materializarse algunos años más tarde, cuando la fundación de las Facultades de Ciencias impulsó un nuevo plan de dotación de materiales y adecuación de espacios.

En cuanto a los instrumentos con los que debía dotarse el laboratorio, Villanova enumeraba un grupo de utensilios muy básicos que podía clasificarse «en varias clases ya según la forma, que es el método más científico, ya según su materia, que es más económico y relativo al costem. Siguiendo esta última clasificación los instrumentos de química que debian equipar el laboratorio podían agruparse en instrumentos de "hierro, hoja de lata, cobre, bronce, latón, plomo, estańo, piedra, vidrio, barro, madera y otros materiales ${ }^{25}$. El archivo universitario conserva diversas facturas de compra de instrumentos y productos químicos entre 1791 y 1807 . En un grupo muy limitado de casos se indica en las facturas el uso que se pretendía realizar de los instrumentos. Así, se indica la compra de "vasos y botellas para encender el oxígeno", "cazuelas de dos piezas para sacar flores de benjuín o cuatro recipientes para

${ }^{24}$ Descripción del local que necesita la cátedra de química de esta universidad y nota de los instrumentos, aparatos y demás efectos que debe tener su gabinete y laboratorio, ca. 1846-47. AUV (Fac. Ciencias, C 306 (1)).

${ }^{25}$ Anuncios publicados en el Diario de Valencia, informando sobre las actividades del "Elaboratorio Químico", entre enero y mayo de 1791 , recogidas en TEN, "La ciencia experimental...* op. cit., págs. 313-317. Pueden ser consultadas en http://digitheka.uv.es/ 
"hacer la piedra infernal». También se adquirieron varios alambiques, retortas, evaporadoras y un "aparato pneumático de vidrio". La mayor parte de las compras, sin embargo, corresponden a objetos tradicionales del laboratorio químico del siglo XVIII: varios hornos de diversos tipos, fraguas y fuelles, un grupo de pesas y medidas y varias balanzas, así como numerosos recipientes de vidrio y barro, junto a morteros, espátulas y crisoles. Se trataba en su mayor parte de unos utensilios que, como señalaba Villanova, podían encontrarse en la más modesta de las oficinas farmacéuticas.

No se diferenciaba mucho este primer laboratorio del que, casi cuatro décadas más tarde, recogía Ramón Teruel en su Nota de los instrumentos, maquinas, y efectos que existen en el laboratorio de la cátedra de química general de esta Universidad elaborada al igual que la de física como preparativo de la gran compra de instrumentos que entonces se organizó. Ramón Teruel nos presenta un instrumental formado fundamentalmente por objetos sencillos susceptibles de ser utilizados y combinados de diferente modo para realizar una gran variedad de experiencias de diversa dificultad: recipientes de metal, vidrio, gres o porcelana y piedra, como matraces, cubas, campanas, probetas, tubos encorvados, frascos, vasijas, vasos y copas, crisoles, cápsulas, retortas, morteros, platillos y tazas, sartenes y calderas, balones y embudos y hasta una gran pila de piedra para el mercurio, así como utensilios para la manipulación de estos objetos como tenazas, triángulos, anillos, llaves de paso, obturadores, toberas, generalmente en cantidades de una o dos unidades. Para las operaciones químicas en caliente se contaba con dos hornos, uno de reverbero y otro de copela de D'Arcet, un hornillo elíptico de copela de barro y otro ordinario de piedra y dos muflas.

Entre esta multitud de recipientes y utensilios, el laboratorio apenas contaba con instrumentos sofisticados o dispositivos especialmente diseñados para una operación concreta. Aparte del alambique de latón, destinado a las operaciones de destilación y un modelo del famoso "soplete de Berzelius», en este caso "de latón con embocadura de marfil y punta de platino", podemos encontrar en este laboratorio dos piezas que cabrían en esta categoría, en ambos casos relacionadas con las experiencias de análisis y síntesis del agua. Una de ellas es el "aparato para descomponer el agua por la pila galvánica», acompañado de una "pila de Bunsen" y una "pila galvánica de cajón». La otra, tres ejemplares de eudiómetro, uno de cristal con armadura de hierro, otro de válvula con armadura de latón y un tercero de «deutóxido de azoe». Cerraban la colección de objetos de este tipo un reducido grupo de instrumentos de medida o 
de análisis cuantitativo, entre los que se encontraban un alcalímetro, dos areómetros de Baumé con los que era posible determinar la concentración de una sustancia en disolución, un termómetro de mercurio y dos balanzas, una de ellas "fina de análisis».

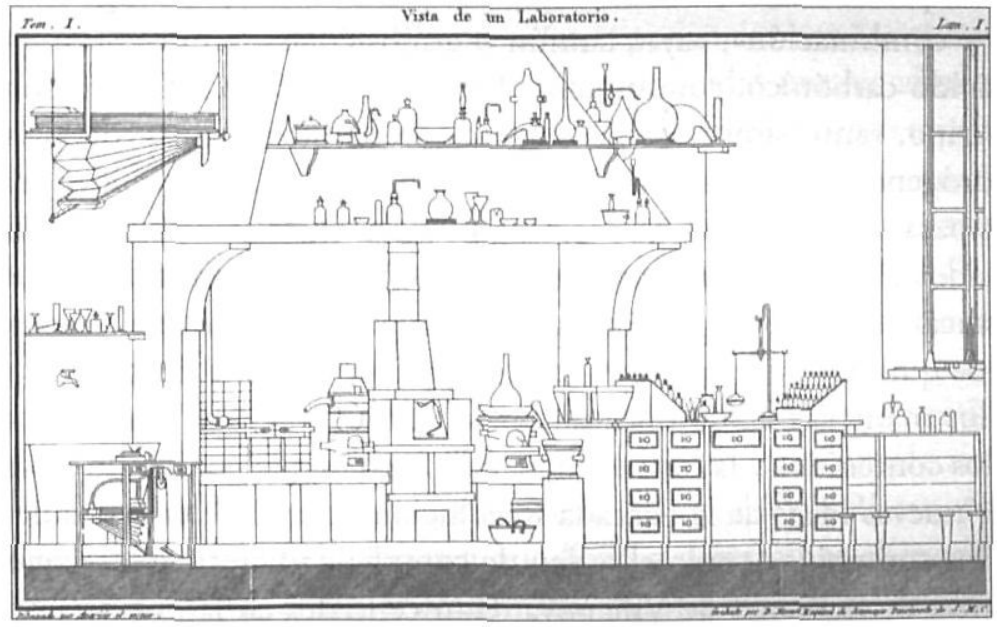

Figura 2

Colección de útiles básicos de un laboratorio de química recogidas en una de las láminas finales del Curso de química general aplicada a las artes publicado en Paris, entre 1804 y 1805, por Josep Garriga i Buach y José María San Cristóbal

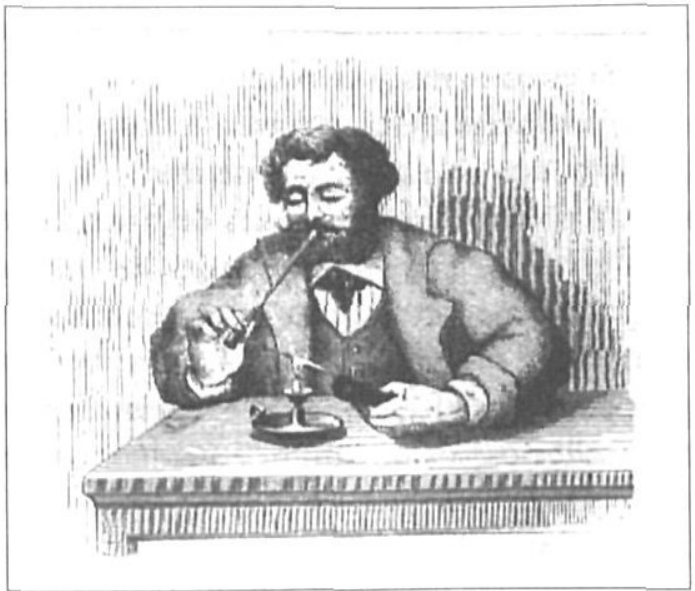

Figura 3

Soplete de Berzelius según un grabado procedente de los Eléments de chimie de P.P. Dehérain (Paris:Libraire de L. Hachette et Cie.1867) 
Sobre las experiencias didácticas que fueron realizadas con estos utensilios algo sabemos a través de los anuncios que de forma periódica aparecieron en la prensa de noticias local, entre enero y mayo de 1791. Siguiendo el orden cronológico de aparición de dichos anuncios, sabemos que fueron realizadas demostraciones experimentales sobre las «leyes de las afinidades», "el fuego en estado de libertad y combinación", "ayre cumún o atmosférico", "combustión y respiración», «ácido carbónico, comúnmente llamado Ayre fixo», "Gas ácido muriático, o marino, tanto simple como oxigenado que otros llaman deflogisticado", "Gas hidrógeno o Ayre inflamable", propiedades físicas y químicas del Agua y métodos para su análisis, los ácidos, las sustancias metálicas y las combinaciones de los ácidos con las "vases" para dar "sales". De esta secuencia de experiencias, cabe destacar en primer lugar que en su orden puede reconocerse el índice de un manual de química de la época. Aunque no puede hablarse de una estructura típica de los manuales de química de finales del siglo XVIII, entre otras razones porque los contenidos y las estructuras tradicionales estaban siendo replanteados desde las nuevas ideas de la llamada Revolución química ${ }^{26}$, criterios de ordenación de los contenidos como el orden de complejidad creciente, reconocible en la secuencia de lecciones de Villanova, eran centrales en la organización de los manuales. También es posible establecer conexiones entre algunos de los instrumentos antes citados y las experiencias anunciadas. Por ejemplo, las de análisis y síntesis del agua, entre las que no debió faltar la electrolisis practicada con el "aparato para descomponer el agua por la pila galvánica».

Algo más difícil es saber cómo fueron realizadas las experiencias que apoyaron las explicaciones de estos temas y el modo en que participó el público de alumnos y de gentes convocadas a ellas a través de los anuncios de prensa. Podemos imaginar que la puesta en escena no fue muy diferente a la que hemos descrito más arriba para el caso de las lecciones de física, en el que las explicaciones dictadas por el profesor eran acompañadas de demostraciones experimentales cuya principal misión era la de ilustrar o confirmar las ideas, principios o técnicas enunciados oralmente. Pero, como venimos subrayando, a diferencia de lo que ocurría en el caso de la física, las demostraciones experimentales diseñadas para los cursos de química añadían una pretensión adicio-

26 B. BenSAUde-VINCENT "A View of the Chemical Revolution Through Contemporary Textbooks: Lavoisier, Fourcroy and Chaptal», British Journal for the History of Science, 23 (4) (1990), 435-460. 
nal, que iba más allá de la observación pasiva del espectáculo didáctico ofrecido desde la cátedra. No se trataba sólo de ilustrar las explicaciones previamente expuestas por el profesor, sino, además, como señalaba el texto del Plan Blasco, poner a los estudiantes en grado de repetirlas por sí mismos. No sabemos hasta qué punto esta pretensión fue más allá de la retórica propia de un documento programático como el del rector Blasco, si las experiencias con las que se acompañaban las lecciones podían ser realmente reproducidas por los alumnos asistentes o si, aun siendo fácilmente reproducibles, fueron realmente repetidas por alguien de los allí presentes. La ausencia de fuentes directas como cuadernos de estudiantes o ejercicios prácticos propuestos hacen difícil ir mucho más allá de lo que las intenciones de profesores y responsables académicos nos dicen. Nos quedan, sin embargo, algunas fuentes indirectas que, analizadas desde esta perspectiva, permiten afirmar que, independientemente del grado en que pudiese hacerse realidad, la idea de una enseñanza fundamentada en la "repetición" de las experiencias químicas por parte del alumno, aprendiz o simple auditor de los cursos de química, tal y como aparece reflejada en el Plan Blasco, fue extremadamente recurrente en esa época y que llegó a determinar el modo en que autores, profesores y responsables académicos plantearon sus manuales, lecciones y cursos de química.

Cabe señalar, en primer lugar, que la "repetición» de las experiencias era, a finales del siglo XVIII, una práctica habitual entre las actividades de investigación habituales para un practicante de la química. Repetir experiencias descritas en las principales revistas científicas y publicar en ellas a su vez los resultados confirmatorios o en su caso las críticas, variaciones observadas, diferentes interpretaciones o mejoras en el proceso era una actividad que ocupaba buena parte del tiempo de los investigadores y en la que podían llegar a participar y realizar contribuciones relevantes químicos de muy diferente condición, dedicación y prestigio. Repetir y mejorar los métodos de preparación, análisis o identificación de la naturaleza y propiedades de las sustancias era una tarea que ligaba las actividades de investigación y de enseñanza, si es que una y otra tarea pueden considerarse como actividades claramente diferenciadas en esos años. La composición de un nuevo manual, por ejemplo, implicaba para sus autores la repetición y comprobación de las experiencias en él descritas. Así nos lo hacía saber el propio Lavoisier quien consideraba que para elaborar correctamente su célebre Traité élémentaire de chimie se había hecho necesario "recommencer peut-être les trois quarts et (plus) des expériences faites jusqu’à ce jour»; una tarea que él no había podido realizar en su totalidad, razón por la cual el resultado no era más que «un 
ouvrage imparfait ${ }^{27}$. Incluso la preparación de los cursos y de las experiencias en ellos demostradas era una ocasión para revisar los experimentos preparados que podía dar lugar a observaciones o mejoras dignas de ser publicadas. Un ejemplo de ello nos lo proporciona el testimonio de Mateu Orfila i Rotger (1787-1853), uno de los alumnos de Villanova que desarrolló toda su carrera profesional en Francia ${ }^{28}$. De acuerdo con lo recogido en sus memorias, fueron sus cursos privados los que le condujeron a uno de sus principales descubrimientos, que le abriría las puertas de las investigaciones toxicológicas. En abril de 1813, mientras estaba realizando una clase sobre el ácido arsenioso, Orfila formó los precipitados que caracterizan a esta sustancia delante de un grupo de más de ciento cincuenta alumnos y afirmó categóricamente que este mismo resultado debía obtenerse en el caso de que el veneno estuviera mezclado con fluidos orgánicos o bebidas como el café, el vino o un caldo. Aprovechando la presencia de un vaso con café, Orfila vertió en él la disolución arsenical y repitió las experiencias pero, para su sorpresa, no pudo obtener los precipitados previstos: el agua de cal dio un precipitado gris violáceo en lugar del color blanco esperado y el sulfato de cobre amoniacal produjo unas deposiciones de color oliva oscuro y no el color verde característico de su reacción con el arsénico. Este acontecimiento inesperado, fruto de la repetición de experiencias para unas clases privadas, condujo a Orfila a estudiar con detalle los riesgos que comportaba la presencia de materias orgánicas en los análisis toxicológicos ${ }^{29}$.

Las experiencias descritas en los manuales o mostradas en los cursos no sólo debían haber sido comprobadas mediante su repetición, sino que, además, debían estar descritas de modo que fueran reproducibles por los lectores. La reproducibilidad es mencionada a menudo por los autores de manuales de

27 Este documento ha sido analizado en B. BenSAude-VincEnt, A.Garcfa-Bel.Mar, J.R. BERTOMEU SÁNCHEZ, L'émergence d'une science des manuels. Les livres de chimie en France (17891852), Paris: Archives Contemporaines, 2003, 36.

${ }^{28}$ Sobre la actividad docente e investigadora de Orfila v. FAYOL, A., La vie et l' oeuvre d'Orfila, Paris: Albin Michel, 1930.; Hernández. MORA, J., "Orfila. El hombre, la vocación, la obra", Revista de Menorca, 49 (1953), 1-121; Bertomeu SÁnCHEZ, J.R.; GarCla Belmar, A., "Mateu Orfila (1787-1853) y las clasificaciones químicas", Cronos, I (2) (1999), 130-152. Una bibliografía extensa, junto con la edición de numerosas obras de Orfila, se puede encontrar en http://www.bium.univ-paris5.fr/histmed/debut.htm.

${ }^{29} \mathrm{La}$ anécdota es contada por Orfila en su autobiografía, que ha sido parcialmente publicada por M.G.Chapel D'espinassoux, "La Jeunesse d'Orfila. Fragment d'une aurobiographie inédite publié par ...", Revue Hebdomadaire, 23 (1914), pág. 96. 
química como un criterio que condicionaba el tipo de experiencias incluidas, el modo de describirlas, el estilo empleado y, por supuesto, los instrumentos utilizados.

Louis Jacques Thénard (1777-1857), autor de uno de los libros de texto de química más influyentes de la primera mitad del siglo XIX, mencionaba en la primera edición de 1813 que había sido especialmente "minucioso en la descripción de las experiencias" porque habla pretendido "poner a los estudiantes en disposición de repetirlas todas" " ${ }^{30}$. La minuciosidad en la descripción de los utensilios y reactivos, de las operaciones realizadas y cada uno de los pasos del proceso, las instrucciones relativas a la manipulación de sustancias y objetos, incluso los pequeños consejos sobre el mejor modo de operar hacía que las narraciones adquirieran un estilo más próximo al de una receta de cocina pensada para ser elaborada que el de una explicación concebida para ser comprendida ${ }^{31}$.

Las detalladas descripciones de los experimentos eran también consecuencia de las limitaciones de las técnicas de impresión para representar gráficamente los fenómenos y los instrumentos descritos en los manuales de química. Hasta los años treinta del siglo XIX no se generalizaron las técnicas de impresión que permitieron intercalar imágenes junto al texto y lograr un mayor grado de definición en éstas ${ }^{32}$. Los manuales de la primera mitad del siglo XIX siguieron utilizando el recurso tradicional de adjuntar al final del libro colecciones de grabados donde eran representados los instrumentos descritos en el interior del texto. Estos grabados eran, por lo general, representaciones lineales de los instrumentos que difícilmente podían permitir la visualización del fenómeno con ellos producido, por lo que era la palabra escrita el único medio para hacer llegar al lector la información necesaria para comprender y, en su caso, reproducir el experimento.

30 L.J.Thenard, Traité élémentaire de chimie, Paris: Crochard, 1813, T.1, págs. ii-iii: "minutieux dans la description des expériences, parce que j'ai voulu mettre les élèves dans le cas de les répéter toutes".

31 Sobre la narración de las experiencias en los manuales de química ver B. BENSAUDEVINCENT, A.GARCIA-BELMAR, J.R. BERTOMEU SÁNCHEZ, L'émergence d'une science des manuels... op. cit. págs. 183-203.

32 Para un estudio de las consecuencias de las técnicas de grabado en los conocimientos cientificos, v. la excelente obra de K. HENTSCHEL, Mapping the Spectrum: Techniques of Visual Representation in Research and Teaching, Oxford: Oxford University Press, 2002, pág. 562. 
Todo ello indica que la voluntad de hacer que los asistentes a los cursos llegaran a ser capaces de repetir por sí mismos los experimentos, tal y como era recogida en el Plan Blasco, no debe interpretarse como un simple y vano ejercicio de retórica académica, sino como el reflejo de un modo común de entender la enseñanza de una ciencia experimental como la química, en la que la repetición de las experiencias por parte de los alumnos era entendida como una actividad obligatoria. La sencillez y facilidad de obtención de los instrumentos empleados por Villanova y mantenida salvo excepciones hasta los inventarios hechos a finales de la década de 1840 se convierte, desde este punto de vista, no tanto en un indicador de una supuesta pobreza de medios, aunque quizás la hubiera, sino en una condición necesaria para que las experiencias demostradas pudieran ser efectivamente repetidas por los oyentes. Pedro Gutiérrez Bueno, también profesor de química en aquellos años finales del siglo XVIII, hacía una mención explícita a esos materiales necesarios para garantizar la formación integral de un químico y que debían estar presentes en cualquier laboratorio dedicado a la enseñanza de esta ciencia:

En vano se esfuerza para aprender esta ciencia el que no junta a la lectura y a la meditación la asistencia a un laboratorio en que observe y execute por sí las operaciones que se propone executar. Hornos de fusión y de copela, hornillas portátiles, alambiques, retortas, recipientes, vasos evaporatorios, matraces, de metal, de vidrio y de barro, aparatos pneumatoquímicos de agua y de mercurio, máquina pneumática, eléctrica, barómetro, termómetro, pyrómetro, gazómetro, hygrometro, calorímetro, etc. son cosos con que se debe comenzar a formar un laboratorio de química. También se necesitan un número competente de minerales y de sustancias vegetales y animales, como gomas, resinas, aceites, huesos, etc. etc. Una colección de reactivos bien hechos y acondicionados, a fin de que sus efectos sean seguros en orden y proporción. En suma se ha de hacer gran provisión de frascos, campanas, y tubos de vidrio de muchos tamaños, un soplete, una mesa con su lámpara de esmaltar para combar los tubos y cerrarlos según se necesite, y otros utensilios que sería largo explicar, y que se pueden ver en este establecimiento y en cualquiera laboratorio bien provisto ${ }^{33}$

${ }^{33}$ P. Gutiérrez Bueno, Curso de Química, Madrid: 1802, vol. I, p. 10. 
Pero, además de que la repetición de estos experimentos fuera materialmente posible, era necesario que existiese un público dispuesto y capaz de hacerlo. Los datos disponibles permiten pensar que también esta segunda condición se cumplía en el caso del auditorio con el que Villanova pudo contar a finales del siglo XVIII. Al igual que muchos otros cursos de química impartidos en universidades e instituciones cientificas europeas del siglo XVIII, los impartidos por Villanova en la Universidad de Valencia estuvieron dirigidos a un público mucho más amplio y variado que el formado por los alumnos oficialmente inscritos en las facultades de artes y medicina ${ }^{34}$. Es muy probable que las clases fueran también seguidas por artesanos interesados en las aplicaciones industriales de la química y médicos, cirujanos y farmacéuticos atraídos por las nuevas herramientas ofrecidas por la química a la explicación y tratamiento de las enfermedades. Quizás también asistió un amplio y variado publico de usujetos libres de las preocupaciones comunes " - por utilizar la expresión con que Pedro Gutiérrez Bueno calificaba a sus oyentes en Madrid unos años antes- para el que las ciencias formaba parte de sus intereses culturales. De nuevo, la ausencia de fuentes directas como registros de inscripción o de asistencia impiden identificar con precisión el público que realmente frecuentó los cursos de Villanova, pero hechos como el de que los cursos fueran públicamente anunciados a través de la prensa local, que se insistiera en la posibilidad de hacer «concurrir cualesquiera otras personas" o que se recordara la importancia de explicar las "aplicaciones a las artes, fábricas y minas" permiten pensar que también en este caso los cursos fueron dirigidos a un público amplio que iba más allá de los estudiantes matriculados en la Universidad ${ }^{35}$. Por otra parte, el peso de este otro público, especialmente el formado por los artesanos, había tenido una importancia central en la propia fundación de la cátedra. La creación de una cátedra de química había sido durante las últimas décadas del siglo XVIII uno de los principales empeños de la Sociedad Económica de Amigos del País. En el informe emitido por Francisco Cabarrús en respuesta a la petición hecha por la Sociedad en 1786 se afirmaba que entre los auxilios que se podían dar «a las fábricas y a las artes", el más

${ }^{34}$ Sobre la evolución de los públicos de la química ver, entre otros, J. GOLINSKI, Science as public culture. Chemistry and Enlightenment in Britain, 1760-1820, Cambridge: Cambridge University Press, 1992.

${ }^{35}$ Sí existen, sin embargo, registros de alumnos para los cursos de Manuel Pizcueta, sucesor de Villanova tras su muerte (Archivo del Museo del Instituto de Historia de la Ciencia y Documentación "López Pińero", Valencia, Fondo Pizcueta, "Discípulos o Cursantes de Química baxo la dirección del Dr. D. Manuel Pizcueta, regente de dicha cátedra vacante por la muerte de D. Tomás Villanovan). 
eficaz era "la enseñanza de la química que por la composición de los simples y su análisis influye especialmente sobre los tintes y tal vez sobre la preparación de las materias primeras para hacerlas susceptibles de recibirlas las fábricas de seda y lana que se hallan distribuidas y establecidas en ese Reyno... " ${ }^{36}$. El propio Villanova en uno de los informes sobre la necesidad de crear una cátedra de estas características hacía especial hincapié en este público de artesanos y en la necesidad de adaptar los contenidos y los métodos de enseńanza a su "talento común" ${ }^{37}$.

Esta pluralidad de públicos, con intereses y capacidades intelectuales y materiales tan diversas, abría toda una gama de posibilidades de hacer realidad la aspiración expresada en el Plan Blasco y recogida por los autores de libros de texto de la época: la repetición de los experimentos por parte de los propios estudiantes. La simplicidad y la accesibilidad de los instrumentos empleados así como la minuciosidad de las explicaciones eran condiciones necesarias para este objetivo. Así lo confirma al menos el testimonio de Mateu Orfila quien, en su vejez, recordaba cómo para compensar la monotonía de los cursos decidió aprender por sí mismo la química a través de las obras de Lavoisier, Berthollet y Fourcroy y de pequeñas experiencias que realizaba en su casa con la ayuda de algunos aficionados a esta ciencia, como Juan Sánchez Cisneros (fl. 1801-1827), un militar ilustrado, que había estudiado en París y que realizó numerosos trabajos relacionados con la mineralogía, la química y la agronomía desde la Sociedad Económica de Amigos del País de Valencia ${ }^{38}$.

En las décadas siguientes, la institucionalización de la enseñanza de la química, la especialización de los públicos, la sofisticación de los materiales didácticos y la aparición de un nuevo tipo de manual adaptado a estas nuevas condiciones materiales, rompió con esta continuidad entre la química artesanal, académica y hasta recreativa, haciendo que en cada uno de estos contextos adquiriera formas muy diferentes. Nos acercaremos a ello a través de los cambios que en las décadas centrales del siglo XIX observaron las colecciones de instrumentos con las que se dotaron

${ }^{36}$ Carta de F. Cabarrús a la R.S.E.A.P.V. , 31-Marzo-1786. Citado en TEN, "La ciencia experimental...", op. cit., p. 289.

${ }^{37}$ Informe de Tomás de Villanova a la R.S.E.A.P.V en torno a la creación de una cátedra y laboratorio de química. Citado por TEN, «La ciencia experimental...», op. cit., pág. 307 y siguientes.

${ }^{38}$ Chapel D'espinassoux, op. cit., pp. 626-629. 
los gabinetes y laboratorios de física y química de las nuevas Facultades de Filosofía, primero, y de Ciencias, más tarde, de la Universidad de Valencia.

\section{«Máquinas» $\mathbf{y}$ «aparatos»}

La primera gran compra de instrumentos de la que existe abundante documentación en el archivo universitario data de los años que siguieron a la creación de la Facultad de Filosofía, en 1845, como consecuencia de la reforma universitaria impulsada por el entonces ministro de la gobernación Pedro José Pidal $(1799-1865)^{39}$. Según el plan, las nuevas Facultades de Filosofía, herederas en cierto modo de las de Artes en su función propedéutica a los estudios superiores, veían ahora ampliados sus fines para dar respuesta a las nuevas necesidades de la sociedad. En efecto, el plan dedicó una especial atención a los llamados estudios secundarios o de filosofía "porque así lo reclaman el estado actual de las luces, la importancia de las clases medias y las necesidades de la industria». Esta nueva enseñanza "propia especialmente de las clases medias" debía ser capaz de cumplir un doble objetivo: suministrar "los elementos del saber indispensables en la sociedad a toda persona regularmente educada" y allanar «el camino para estudios mayores y de adquisición más difícil». Se establecía así un primer ciclo de «segunda enseñanza elemental» de cinco años que conducía al grado de Bachiller y ofrecía una enseñanza "general y formando una suma de conocimientos indispensables a toda persona bien educadan. La presencia de las ciencias en este ciclo elemental se reducía a un curso de aritmética y geometría en el cuarto año y de sendos cursos de "elementos de física experimental y nociones de química" y nociones de historia natural en el quinto año. Para aquellos que desearan acceder a alguna de las Facultades Mayores se instauraba una segunda enseñanza de «ampliación", que "prepara para el estudio de ciertas carreras o sirve para perfeccionar los conocimientos adquiridos en la elemental» y que, tras dos años de estudio, conducía a los grados de licenciado en Ciencias o en Letras, y en Filosofía si se obtenían los dos anteriores. Para los que optaban por las ciencias, el plan in-

${ }^{39} \mathrm{El}$ texto de la ley puede consultarse en hrtp://www.filosofia.org/mfa/fae845a.htm. Sobre el significado de esta reforma en la enseñanza de las ciencias en España, ver J.L PESET; S. GARMA, J. S. PÉrez GARZON, Ciencias y enseñanza en la revolución burguesa, Madrid: Siglo XXI, 1978; M. PESET, J. L. PESET, La Universidad española (siglos XVIII y XIX). Despotismo ilustrado y revolución liberal. Madrid: Taurus, 1974 y A. MORENO GONZALEZ, Una ciencia en cuarentena: Sobre la fisica en la universidad y otras ilustraciones desde la ilustración hasta la crisis finisecular del XIX, Madrid, CSIC, 1988. 
cluía cursos de Matemáticas sublimes, Química general, Mineralogía, Zoología, Botánica y Astronomía física, añadiéndose años más tarde una materia de ampliación de física. También era posible cursar dos años suplementarios hasta obtener el grado de doctor, pero estos estudios sólo podían realizarse en la Universidad Central de Madrid. Más adelante, las Facultades de Filosofía pasaron a formar parte del grupo de Facultades Mayores, ganando así una posición institucional reservada hasta entonces a la jurisprudencia, la teología y la medicina.

Tal y como se indicaba en la "exposición a S.M" el nuevo plan respondía a una "necesidad de establecer unidad y armonía en todas las escuelas del reino" y poner coto así a la situación de arbitrariedad y anarquía que según los autores del plan imperaba en el sistema educativo español:

Antiguamente eran las Universidades independientes entre sí, y hasta del Gobierno mismo; cada cual tenía su régimen, sus estudios, sus métodos y aun sus pretensiones distintas; no sólo disponían arbitrariamente de sus fondos, sino que hasta era también arbitraria en ellas la enseñanza. Ya desde fines del siglo pasado trató el Gobierno de poner diques a semejante anarquía, que, tras el desconcierto general de todas las ciencias, mantenía a éstas en atraso lastimoso, perpetuando rancias ideas, doctrinas desacreditadas y perjudiciales preocupaciones

Se trataba, pues, de lograr un «un sistema uniforme y bien ordenado" que garantizase una formación secundaria y superior adecuada y del mismo nivel en todas las universidades espaniolas. El carácter centralizador y uniformizador del nuevo plan fundamentó muchas de las disposiciones, reglamentos y normativas que lo desarrollaron. En lo que respecta a los contenidos y los métodos de enseñanza, el control de los libros de texto, la fijación de programas de estudios y la elección de los instrumentos didácticos empleados pueden situarse entre las herramientas principales con las que se trató de llevar la uniformización y la centralización en este aspecto esencial de la enseñanza.

El nuevo Plan lanzaba una fuerte crítica y un total rechazo a la libertad total de elección de los libros de texto por parte de los profesores, vigente desde 1836. Considerada esta medida "prematura en España", siendo la responsable de situaciones "escandalosas", protagonizadas por catedráticos que "abusando de su libertad" hablan elegido textos anticuados, desacreditados o sin relación alguna con el 
objeto de la asignatura. Tampoco se manifestaba el gobierno a favor de la elección de un único manual oficial, pues se entendía que esto podía despertar el urecelo de que tienda a comprimir las ideas o establecer un monopolio exclusivo en favor de autores determinados". La justa solución intermedia pasaba para los legisladores por el establecimiento de una lista cerrada de libros de la que los catedráticos podrían elegir los fueran de su mayor agrado. Este método que, como recordaba el texto de la ley, había sido aplicado con éxito en otros países ${ }^{40}$, se autodefinía como un modo de poner "coto a los inconvenientes de la libertad absoluta" a la vez que dejaba «suficiente campo a las personas doctas para dedicarse a la composición de libros útiles", y acaso las favorece, porque el fallo de una corporación imparcial e ilustrada se inclinará siempre al verdadero mérito, mientras el interés propio, la desidia o los compromisos suelen ser causa de que los meros profesores se decidan por obras de valor escasom. En aplicación de esta nueva normativa, fueron publicadas en los años siguientes varias listas de libros recomendados, formadas en todos los casos por traducciones recientes de textos franceses ${ }^{41}$. Para la química, fueron los Elementos de quimica de Bouchardat, traducidos por Gregorio Lezama y Juan Chavarri y el Curso elemental de quimica teórico práctico de Kaeppelin traducido por Rafael Sáez Palacios los dos textos recomendados para las nociones impartidas en el cuarto año de enseñanza secundaria elemental; mientras que para los cursos de química general en los años de ampliación se recomendó la traducción del curso de química en tres tomos de Lassaigne realizada Francisco Álvarez Alcalá. Para la fisica experimental, los nuevos catedráticos de enseñanza secundaria podían elegir entre los cursos de física de Despretz, Beudant, Deguin y los elementos de física de Pouillet. A partir de 1848, las listas comenzaron a incluir libros producidos por autores españoles, en ocasiones los mismos que habían sido los responsables de las traducciones utilizadas en los primeros años. Los "cursos elementales de física y nociones de química» de Venancio González Valledor, Juan Chavarri, Gerardo Morquecho y Francisco de Paula Montells y Nadal, el umanual de física y nociones de química" de Manuel Rico y Mariano Santiesteban y el de Manuel Fernández

${ }^{40}$ Sobre la implantación de este sistema en Francia ver A. CHOPPIN, Les manuels scolaires: histoire et actualité, Hachette: Paris, 1992; B. BELHOSTE, Les sciences dans l'enseignement secondaire en France, t. 1, 1789-1914, INRP: Paris, 1995; y B. BeLHOSTE, "Les caractères généraux de l'enseignement secondaire scientifique de la fin de l'Ancien Régime à la Première Guerre mondiale, Histoire de l'education, 41 (1989), 3-45.

${ }^{41}$ Real Orden, de 22 de agosto de 1846, aprobando las listas de obras de texto presentadas por el Consejo de Instruccion puiblica y Real orden de 8 de septiembre de 1847, aprobando las listas de obras presentadas por el Consejo de Instrucción pública. 
Figueres, o el «curso elemental completo de física experimental» de Fernando Santos de Castro fueron las obras que de manera invariable figuraron en las listas publicadas durante las dos décadas siguientes ${ }^{42}$. Aunque el Plan Pidal dejaba libertad en la elección de libros para los niveles de enseñanza universitaria superior, desde 1858 comenzaron a aparecer también listas de libros recomendados para las materias impartidas en las Facultades de Ciencias ${ }^{43}$.

Menos explícito fue el plan en lo relativo a los métodos didácticos que debían emplearse. Aunque se dedicó algo de atención al orden y métodos empleados en la enseñanza de los contenidos generales asignados a la secundaria elemental, al tratar este punto en el caso de los estudios de ampliación, el plan se limitaba a señalar que «no ha sido preciso tanto esmero en esta parte de la segunda enseñanza", siendo suficiente en este nivel educativo «reunir las ciencias que pueden servir de preliminar a las diferentes carreras, para que cada cual vaya a buscar como en un vasto almacén los conocimientos que necesitem. El plan establecía, sin embargo, otras medidas que, de forma indirecta, condicionaron esta aparente libertad concedida a los profesores y alumnos para elegir el modo de buscar en ese inmenso almacén de la ciencia. Y éstas pasaban por la elección del tipo de materiales didácticos que debían utilizarse para la enseñanza de las distintas materias y, muy especialmente, de las ciencias. El plan del ministro Pidal contempló las necesidades específicas de material didáctico de cada una de las materias impartidas en la enseñanza secundaria elemental y de ampliación. En el caso de la física y de la química, el artículo 173 del «Reglamento para la ejecución del Plan de Estudios» señalaba que los centros deberían disponer de un "gabinete de física con todos los aparatos que exige la enseñanza elemental de esta ciencia» y de un «laboratorio de

42 Sobre los manuales de química en España durante el siglo XIX v. J.R. BERTOMEU SÁNCHEZ; A. GARCIA Belmar, "Spanish chemical textbooks (1800-1845). A bibliographical approach". En: B. BENSAUDE-VINVCENT; A. LUNDGREN (eds.), Comunicating Chemistry: Textbooks and their Audiences, 1789-1939. Canton, History of Science Publications, 1992, págs. 19-55 y J.R. Bertomeu Sanchez, A. Garcia Belmar, "Los libros de texto de química destinados a los estudiantes de medicina y cirugía en España (1788-1845)", Dynamis, 20 (2000), 230-245. Para los libros de texto de física, ver MORENO GONZÁlEZ, Una ciencia en cuarentena... $o p$. cit. La legistlación respecto a estas obras ha sido recogida en los trabajos que han surgido del proyecto MANES: J.L.VILLALAIN BENITO, Manuales escolares en España. Tomo I. Legislación (1812-1939). Tomo II. Libros de Texto Autorizados y Censurados (1833-1874), Madrid: UNED, 1997-1999.

${ }^{43}$ Real Orden de 25 de septiembre de 1858 , aprobando las listas de obras de texto para las Facultades de Filosofía y Letras, Ciencias, Farmacia, Medicina, Derecho y Teología. 
química con los aparatos y reactivos necesariosn" ${ }^{44}$. Para que así fuera, se puso en marcha un ambicioso plan de compra de instrumentos y material de laboratorio, estrechamente dirigido y ejecutado desde el Ministerio de la Gobernación por su titular Pedro José Pidal, y desde la Dirección de Instrucción Pública por Antonio Gil de Zárate, dentro de la ya mencionada política centralizadora y uniformizadora que caracterizó la reforma educativa de $1846^{45}$.

El primer paso consistió en el nombramiento de una comisión encargada de evaluar la situación en cada universidad y determinar el número y tipo de instrumentos que era necesario adquirir para equipar los gabinetes y laboratorios de las cátedras de física y química, tanto de las nuevas facultades de filosofía como de las de medicina y farmacia. Para ello, se envió a todas las Universidades una Circular previniendo a los Institutos se provean de los instrumentos necesarios para la explicación de las ciencias fisicas y naturales en la que se especificaban los objetivos perseguidos y los medios disponibles para dotar a las nuevas cátedras de "todos los medios materiales necesarios para que las lecciones sean tan provechosas como se debe desear, sobre todo, en las ciencias físicas y naturales, que no solo requieren explicaciones verbales, sino también el examen de los objetos, y los experimentos y manipulaciones indispensables para la cabal inteligencia de las materias” ${ }^{46}$. La Circular fue acompañada de un Catálogo modelo de las máquinas é instrumentos necesarios en una Cátedra de Física experimental, así como de un $\mathrm{Ca}$ tálogo modelo de aparatos y demás objetos que debe haber en una cátedra de quimica general y su laboratorio, que los destinatarios debían utilizar para elaborar los informes sobre los materiales existentes y aquellos que era necesario adquirir. Los dos catálogos modelo fueron elaborados a partir de los instrumentos y precios disponibles en los catálogos de los fabricantes franceses Lerebours y Pixii. El de física experimental contenía una lista de 152 piezas valoradas en 9.531 francos y el de química 133 valorados en 6.448 francos, lo que en total sumaba algo más

${ }^{44}$ El reglamento, publicado el 22 de Octubre de 1845, puede consultarse en (http://www.filosofia.org/mfa/fae 845 b.htm)

${ }^{45}$ En algunos casos, la renovación del instrumental didáctico para la enseñanza de las ciencias había contado con iniciativas impulsadas desde las propias universidades. En el caso de Valencia, existen noticias del viaje a Francia, Bélgica e Inglaterra realizado en 1848 por el catedrático de química general, José Monserrat y Riutort, con el doble fin de ampliar su formación y gestionar la compra de instrumentos de física y química para las nuevas cátedras (V. PeSET CerverA, "José Montserrat y Ruitort", En: Apologia de Médicos Valencianos, Valencia, 1891).

${ }^{46}$ Boletin Oficial de Instrucción Pública, Tomo XI, Año VI, no 17, 1846, p. 545-557. 
de 60.000 reales de vellón. Además del fin didáctico señalado en primer lugar, la circular preveía un segundo uso de los instrumentos incluidos en las listas al servicio de las tareas de investigación que se esperaba realizasen los nuevos catedráticos:

Los profesores de dichas ciencias, no deben limitarse a la mera enseñanza, no cumplirían sólo así con su importante encargo; es preciso que animados de un noble amor patrio e impulsados del ansia de saber y de ilustrarse se dediquen a útiles trabajo y aspiren a que su nombre suene entre los que procuran adelantos a esta parte de los conocimientos humanos. Así recobrará España el puesto que antes tenía entre las naciones ilustradas, y así prosperará entre nosotros la industria que dichas ciencias vivifican y engrandecen ${ }^{47}$.

Esta doble función de los instrumentos al servicio de la enseñanza y de la investigación fue también tenida en cuenta a la hora de elegir los fabricantes a los que se realizarían los encargos. En una Real Orden de noviembre de 1846, por la que se hacía efectivo el mandato de adquirir "los instrumentos y aparatos de física y química para proveer a las universidades» se recordaba la importancia de «la bondad de los aparatos", puesto que al estar "destinados no solamente a las explicaciones en la cátedra, sino también a los experimentos y trabajos que han de hacer los profesores para los adelantos de las ciencias, deben ser de primera calidad y tomados a prueba». Fue este doble uso el que se tuvo en cuenta al tener que optar entre dos de los principales "maquinistas" de Paris. De Lerebours se reconocía su fama por la "solidez y perfección" de sus productos, aunque también por los altos precios de éstos. Frente a él, el carálogo del "maquinista" Pixii, ofrecía una mayor «baratura», pero también el inconveniente de que "sus objetos no suelen ser de construcción tan perfecta, sirviendo para las demostraciones en la cátedra, pero no tanto para los experimentos y trabajos científicos". Como podremos comprobar, finalmente fueron la baratura y el uso didáctico los dos criterios que determinaron la elección de los fabricantes, siendo la casa Pixii la que mayor volumen de encargos recibió.

El catálogo modelo se inscribía así, junto a los programas y las listas cerradas de libros de texto elegibles por el profesor, entre las herramientas de control y

${ }^{47}$ Id. p. 546. 
uniformización de la enseñanza utilizadas por el gobierno. El catálogo definía los límites precisos de una colección cerrada de objetos didácticos que debían servir para instruir en unos conocimientos delimitados por los programas y los libros de texto. La interacción entre programas, libros de texto y colección de instrumentos era extremadamente estrecha, hasta el punto de que muchos de los temas incluidos en los programas eran enunciados a través del instrumento con el que debía mostrarse tal cuestión de la física o de la química.

Pero, independientemente del grado en que éstos instrumentos pudieron contribuir a delimitar y definir el contenido de los cursos, nos interesa ahora preguntarnos por los cambios significativos en las características de estos instrumentos y el modo en que los nuevos materiales pudieron contribuir a cambiar el modo de impartir tales contenidos. Como ya hemos señalado más arriba, fue el catedrático de astronomía Ramón Teruel el responsable de la elaboración de los inventarios de los instrumentos que se conservaban en el "laboratorio de la cátedra de química general" y en el "Gabinete de Física" de la Universidad de Valencia. Fue también encargado de comparar el material existente con el recogido en el catálogo modelo y elaborar la Nota de los instrumentos y aparatos de Física y quimica e igualmente de Matemáticas, que faltan en los respectivos gabinetes que debía ser remitida al gobierno para que se tuviera en cuenta en la compra de materiales y su posterior distribución entre las universidades. En total se solicitaron más de un centenar de objetos (entre ellos colecciones completas de sustancias, recipientes y utensilios de varios tipos) cuyo valor estimado según el "coste en las fabricas de Paris" era de 42.812 reales de vellón, a lo que, si se añadía el $25 \%$ uen que pueden calcularse los gastos de embalaje conducción y derechos de Aduanas", se llegaba a la suma de 53.515 reales. Una cantidad que se aproximaba mucho a los 60.000 reales que costaban los instrumentos reunidos en los dos catálogos modelo ${ }^{48}$.

A partir de los informes recibidos desde las diferentes universidades, la comisión gubernamental elaboró una memoria en la que se fijaron las listas de instrumentos y se presupuestó el coste aproximado. Gil de Zárate narró años más tarde

${ }^{48}$ Se conserva también la nota correspondiente a los materiales de mineralogía y zoología solicitados para la cátedra de Historia natural (Inventario de las maquinas instrumentos y objetos que faltan para completar los Gabinetes de Flsica, Quimica e Historia Natural (AUV. Fac. de Ciencias, C. $306(1))$ 
en su conocido texto De la instrucción pública en España el viaje que realizó a París en noviembre de 1846 para gestionar la compra de los instrumentos solicitados por las universidades ${ }^{49}$. Acompañado del profesor de física Juan Chavarri (1813-?) y con el asesoramiento del entonces decano de la Facultad de Medicina de París, el menorquín Mateu Orfila i Rotger (1787-1853), Gil de Zárate afirma en este documento haberse encargado personalmente de negociar con los principales fabricantes de instrumentos de París las condiciones de compra y entrega del abultado pedido. Fueron tres los fabricantes que finalmente concentraron los encargos, "Pixii i Deleuil para los instrumentos de física; Lizé y Clech para la cristalería y porcelana; y los hermanos Rousseau para los productos químicos». La disponibilidad de un crédito de 160.000 francos, abierto en la "casa del Sr. Aguirrebengoa, banquero del gobierno español en París" permitio, según el autor del informe, garantizar los pagos al contado y obtener de este modo importantes rebajas respecto al precio fijado en los catálogos utilizados para elaborar el presupuesto inicial. De este modo, se lograron adquirir por 116.597 francos los instrumentos inicialmente presupuestados en 144.345 francos y dedicar la cantidad restante a comprar instrumentos y colecciones no incluidas en las listas iniciales. Gil de Zárate concluía su informe subrayạndo que con «600.000 reales escasos se pondrán al completo los gabinetes de física y los laboratorios de química de las universidades, algunas de las cuales carecen hoy día casi absolutamente de estos objetos indispensables para la sólida enseñanza, y quedarán todas en esta parte al nivel de los establecimientos extranjeros". Según el informe, los instrumentos adquiridos fueron distribuidos entre las universidades y se procuró que los envíos fueran realizados directamente a los lugares de destino durante el año o año y medio que se había establecido como plazo de entrega.

La documentación conservada en el Archivo de la Universidad de Valencia muestra que los materiales comprados y distribuidos desde Madrid fueron una parte ínfima, comparada con la enviada directamente a la Universidad de Valencia por los fabricantes franceses. El documento final en el que se relacionó

${ }^{49}$ El resultado de este viaje fue expuesto en una memoria dirigida al Ministro de Comercio, Instrucción y obras Públicas, que fue publicada como anexo a la «Real Orden por la cual se manifiesta al señor director general de instrucción pública que S.M. ha visto con agrado el buen éxito de la comisión que llevó al extranjero para adquirir máquinas y útiles necesarios en las universidades", Boletín oficial de Instrucción Pública, IX, año VIII, $n^{\circ} 5,1847$. La obra mencionada de Gil de Zárate fue publicada en Madrid, Colegio de Sordomudos, 1855, 3 vols. 
el Estado que manifiesta los aparatos y utensilios de Física y Quimica contratados para la Universidad de Valencia y la distribución que de ellos debe hacerse entre las facultades de Ciencias y Medicina tan solo recoge una pequeña lista de «aparatos que se remitirán desde Madrid", todos ellos recipientes y utensilios sencillos para diversas operaciones de laboratorio y que, en general, correspondían a los instrumentos que en el catálogo modelo se mencionaban en la «Nota de los útiles de química que pueden adquirirse en Españan. El resto fue una extensa lista de objetos y colecciones de minerales y sustancias químicas que "se recibirán directamenten, en las que figuraban algo más de 200 aparatos e instrumentos de física y química, más de un millar y medio de objetos de vidrio (retortas, probetas, tubos, frascos, matraces, obturadores, morteros, copas, vasos, crisoles, cápsulas, crisoles, copelas, etc.) y dos colecciones de sustancias químicas, una "de productos químicos para la enseñanza" y otra de "productos para la cátedra de química médica». Según se desprende de las facturas de compra y de los certificados de entrega de las compañías transportistas estos instrumentos llegaron directamente a Valencia desde París, a través del puerto de Marsella en los paquebotes de vapor de varias compañías navieras españolas como Vidal Hermanos o Dotrés Clavé \& Fabra ${ }^{50}$.

Las facturas de compra nos permiten evaluar de manera aproximada el volumen global de instrumentos adquiridos y su valor total. Entre octubre de 1847 y septiembre de 1848 se pagó a la casa francesa Pixii et fils un total de $5.546 \mathrm{~F}$ por la compra de 112 instrumentos de física y química. También se conservan varias facturas con el membrete de "Deleuil opticien, constructeur d'instruments de physique» fechadas entre abril y julio de 1847 en las que se recogen un total de 85 instrumentos de física y química valorados en $4.515 \mathrm{~F}$. Las dos colecciones de sustancias químicas solicitadas en el informe de Teruel fueron adquiridas en julio de 1847 a Rousseau fréres, al precio de $508 \mathrm{~F}$ la de 200 productos químicos para la enseñanza y $608 \mathrm{~F}$ la de 150 "produits chimiques médical. Sin poder asegurar que las facturas conservadas cubran el total de los instrumentos destinados a la Universidad de Valencia, puede comprobarse a partir de las que aquí hemos contabilizado que el costo total de las adquisiciones - 11.177 francos - es aproximadamente una décima parte del total de las compras realizadas por Gil de Zárate para los once gabinetes y laboratorios de las universidades españolas contempladas en el informe elaborado por la comisión.

${ }^{50}$ AUV, Facultad de Ciencias, C-292. 


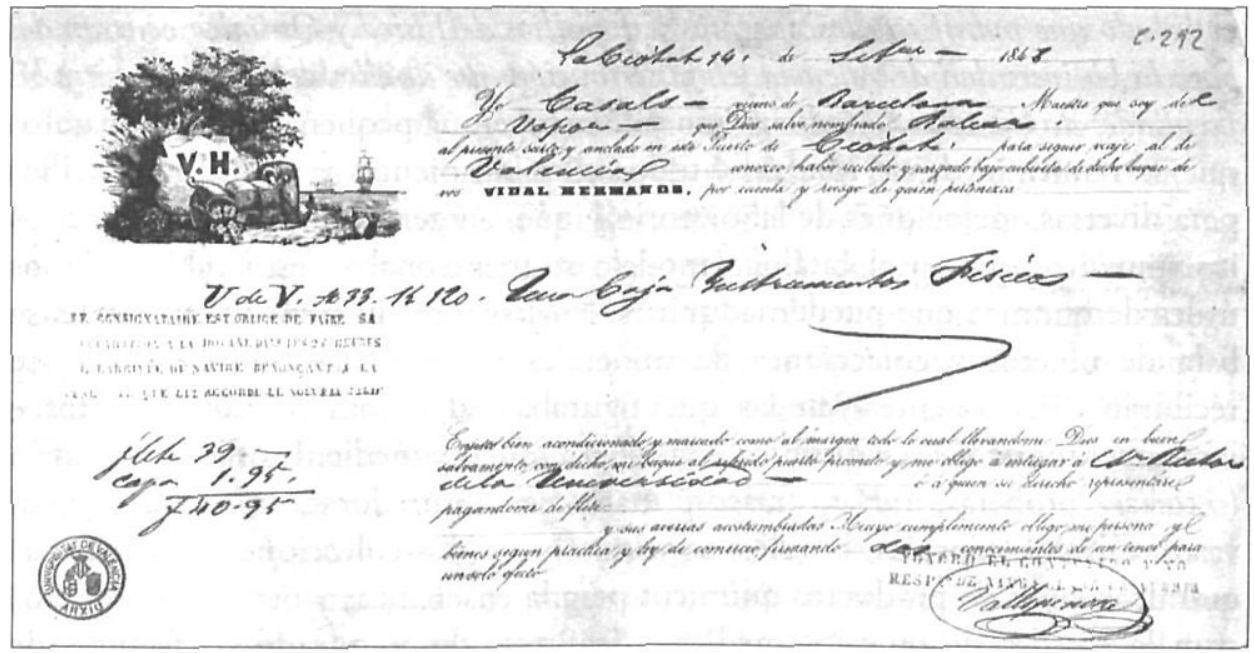

Figura 4

Notas de entrega de mercancía de una de las compañías navieras responsables del traslado de los instrumentos adquiridos en París entre 1847 y 1848 , y enviados a Valencia a través del puerto de Marsella. (Archivo de la Universidad de Valencia)

La comparación entre los inventarios que Ramón Teruel hizo de los instrumentos existentes en 1846 y las listas de instrumentos solicitados y finalmente comprados entre 1847 y 1848 permite avanzar algunas respuestas a la pregunta planteada más arriba acerca del grado de innovación que esta gran compra de instrumentos supuso para el gabinete de física y el laboratorio de química y, por ende, para la enseñanza de estas materias ¿̨e trataba únicamente de una renovación y actualización del material existente, o con los nuevos instrumentos llegaron también objetos de características diferentes que implicaran métodos de enseñanza distintos a los practicados hasta ese momento? Esta pregunta tiene a nuestro entender respuestas diferentes cuando la comparación se establece entre los viejos y nuevos aparatos y máquinas del gabinete de física, o cuando se hace entre los "efectos» del laboratorio de química iniciado por Villanova y las nuevas "máquinas y aparatos» con las que se dotaba ahora el laboratorio de la cátedra de química general recientemente ocupada por Josep Montserrat i Ruitort (1814-1881).

Cabe destacar, en primer lugar, que del centenar largo de instrumentos y máquinas de física registrados en los inventarios realizados entre 1846 y 1847 por el profesor Teruel, algo más de un tercio figuraban también en el Inventario de las 
maquinas y aparatos que existen en el Gabinete de esta Universidad comprendidos en el catalogo modelo publicado por la Direccion de estudios en el Boletin de instruccion publica. La fuerte línea de continuidad que este grupo de instrumentos marcaba entre la nueva colección definida por el catálogo y el viejo gabinete nos remite a algunas de las máquinas más clásicas de la enseñanza de la física. Entre ellas, la máquina de Atwood, la gran máquina pneumática de dos cuerpos «según el método de Babinet" o la "Grande maquina eléctrica», muy similares - si no las mismas - a las fabricadas a finales del siglo XVIII por el maquinista Pérez. También figuraban en este grupo de intersección numerosos accesorios, principalmente de la máquina eléctrica, como las botellas de Leiden, un electróforo, tres pistoletes de Volta, un taburete aislado, el cuadro mágico de Franklin, etc. Otros ejemplos de instrumentos ya existentes recogidos en el nuevo catálogo son aparatos como el de Haldat, un modelo de balanza hidrostática con sus accesorios; algunos de los tipos de prismas, lentes y espejos recomendados para el estudio de la óptica, así como los ya mencionados microscopios y telescopios; varios objetos sencillos como imanes naturales y brújulas o modelos muy simples para el estudio de las leyes de la mecánica como cuatro bolas de marfil y un arco graduado para el estudio de los choques de los cuerpos, un plano inclinado con sus correspondientes objetos de diferente forma y peso o una máquina para el estudio de las fuerzas centrales y sus accesorios para el estudio de las fuerzas centrifugas y centrípetas. También estaban recogidos en el catálogo modelo parte de los termómetros y barómetros de meteorología, así como un higrómetro de Saussure.

La parte del gabinete que el nuevo catálogo dejaba en cierto modo obsoleta, al no incluirla entre los instrumentos necesarios para un curso de física, estaba en parte formada por instrumentos pertenecientes a partes de la física que en el nuevo catálogo habían quedado drásticamente reducidas. Este es el caso, por ejemplo, de los más de veinte instrumentos del gabinete dedicados al estudio de los fenómenos acústicos, una parte de la física para la que el catálogo tan solo contemplaba como necesarios un sonómetro, tres láminas vibrantes y dos arcos, uno de bajo y otro de contrabajo. Algo similar ocurría con las cuatro esferas -celeste, terrestre, armilar y ptolemaica - disponibles en el gabinete para el estudio de la geografía. El resto son instrumentos o accesorios para el estudio de la electricidad, la óptica o la hidráulica, que dejan de aparecer en el catálogo o que fueron sustituidos por modelos diferentes. Entre los primeros cabe destacar las dos máquinas electromagnéticas de Pouillet y de Clarke, que no fueron recogidas ni sustituidas por modelos diferentes en el catálogo modelo. Por último, entre los objetos sustituidos por versiones diferentes pueden ci- 
tarse, por ejemplo, el "electroscopio de bolitas de médula de saúco", que es sustituido por modelos de otros materiales, o el grupo de balanzas analíticas que en el nuevo catálogo son sustituidas por una balanza de Roberval y un «aparato para la teoría de la balanza».

Pero, ¿qué eran esos casi setenta objetos recogidos en el nuevo catálogo modelo y de los que los inventarios de 1846 no hacen mención alguna? Podemos distinguir también aquí varios grupos. Uno de ellos es el de los instrumentos clásicos ausentes en los inventarios anteriores, probablemente por falta de presupuestos o dificultad de fabricación. Un ejemplo es el de los famosos hemisferios de Magdeburgo, el modelo original de la pila de Volta vertical, el tubo de Mariotte, la marmita de Papin, la balanza de Coulomb, o un modelo del barómetro de Torricelli. También habría que incluir en este grupo la larga lista de instrumentos didácticos clásicos que el catálogo modelo incluía y que no figuraban en los catálogos, entre ellos algunos casi juguetes como el ludión, la fuente de Herón o el molinete hidráulico utilizados en las lecciones de hidráulica. También encontramos entre las novedades modelos nuevos de aparatos ya existentes, como es el caso de los varios tipos de excitadores electromagnéticos - simple, universal, de mango de cristal, etc.- que se unen al "escitador" mencionado en los inventarios; los diferentes tipos de pilas - de Volta vertical, de Wollaston, de artesa y de corriente continua- que sustituían al único modelo de pila, la de Bunsen o de carbón - disponible hasta entonces en la colección. Mención especial son las reproducciones o modelos didácticos de instrumentos diseñados durante las primeras décadas del siglo XIX en el marco de nuevas investigaciones. Este es el caso, por ejemplo, del polariscopio de Arago, probablemente uno de los primeros modelos de polarímetros diseñados para el estudio de la actividad óptica de ciertas sustancias químicas ${ }^{51}$, o de instrumentos como el higrómetro de Daniell ${ }^{52}$.

${ }^{51} \mathrm{R}$. WARD, The development of the polarimeter in relation to problems in pure and applied chemistry: an aspect of 19 th century scientific instrumentation, Londres: University of London, 1980.

52 Se trata de un instrumento introducido alrededor de 1820 por John Frederic Daniell (1790-1845). Está formado por dos esferas de vidrio unidas por un tubo en forma de U. En el interior del dispositivo se ubica un termómetro en contacto con un liquido etéreo en una esferas. La segunda esfera se cubre con una tela, sobre la que se vierte un líquido altamente volátil. La consiguiente refrigeración produce una disminución de la temperatura en el interior del tubo que es registrada por el primero de los termómetros. (G. TURNER, Scientific Instruments, 1500-1900. An Introduction, Berkeley: University of California Press, 1998). 
Como puede comprobarse, el nuevo catálogo no introducía novedades sustanciales en el tipo de instrumentos destinados a la enseñanza de la física. En primer lugar, porque buena parte de los instrumentos del catálogo ya formaban parte de la colección del gabinete o porque eran modelos sensiblemente mejorados que sustituían a los ya existentes. Los objetos no fueron abandonados porque la función que desempeñaban había quedado en desuso. La principal causa de obsolescencia fue la variación en el peso que determinados fenómenos tuvieron en los nuevos programas. Se trata, prácticamente en la totalidad de los casos, de instrumentos clásicos diseñados en el marco de investigaciones que habían tenido lugar desde el siglo XVII hasta principios del siglo XIX. Junto a ellos, un grupo de instrumentos, pequeño, pero muy significativo, puede relacionarse con investigaciones recientes. Pero, al margen de su antigüedad o de su novedad respecto a la colección ya existente, el nuevo gabinete de física definido por el catálogo modelo reunía una colección de instrumentos que ni en su concepción ni en los usos a los que estaban destinados diferían de los que medio siglo antes lograba construir José Pérez en su taller. Independientemente de la complejidad, del diseño o de la calidad técnica, se trataba entonces y ahora de máquinas especialmente concebidas y diseñadas para la demostración didáctica de fenómenos físicos particulares o la constatación de leyes y principios concretos.

¿Podemos encontrar una continuidad similar en el caso de los materiales destinados en el catálogo modelo a la enseñanza de la química? Como hemos podido ver a través de las facturas de finales del siglo XVIII hasta los inventarios del laboratorio de química realizados en 1846 contenían, salvo algunas excepciones, una colección de instrumentos, utensilios y recipientes poco sofisticados, que podían ser utilizados y combinados de diferente forma para realizar experiencias sencillas. Muchos de estos instrumentos formaban parte del laboratorio químico tradicional que, como ha señalado Frederic L. Holmes, fue la parte más estable de la química durante los siglos XVII y XVIII ${ }^{53}$. Este tipo de utillaje siguió estando presente de manera mayoritaria en la nueva remesa de material adquirido por la Universidad de Valencia, a instancias del gobierno central y siguiendo las directrices marcadas desde Madrid. El material para los laboratorios de química recogido en el catálogo modelo estuvo constituido fundamentalmente por centenares de recipientes y utensilios similares a los ya disponibles, siendo las nove-

53 Holmes, F.; LeVERE, T., Instruments and Experimentation in the History of Chemistry, Cambridge: MIT Press, 2000. 
dades atribuibles más a las carencias del laboratorio existente en esos momentos que a la inclusión de objetos recientemente incorporados al utillaje químico. Sin embargo, entre las series completas de recipientes, tubos y vasijas de todos los tamaños, formas y materiales el catálogo modelo trajo consigo un grupo de «aparatos» de características muy diferentes de aquellos «utensilios» sencillos, polivalentes y fáciles de adquirir con los que profesores, ayudantes y alumnos habran aprendido a hacer las demostraciones experimentales.

Entre estos nuevos "aparatos», destacan los destinados a las operaciones de análisis cuantitativo. Algunos son modelos más sofisticados de instrumentos ya conocidos. Este es el caso de los nuevos areómetros, como el «universal» o el "alcohómetro centesimal de Gay-Lussac» con el que se construyeron las tablas oficiales para la determinación de los grados de las bebidas alcohólicas en Francia. También se incluían entre los nuevos aparatos un «alambique de Gay-Lussac» diseñados especialmente para "ensayar vinos", un autoclave, dos lámparas de seguridad, una de hidrógeno y otra de Volta, una pila de Wollaston y un «aparato fumigatorio de Guyton de Morveau", instrumento este último empleado para purificar el aire mediante gases ácidos capaces de acabar con los «miasmas pútridos" responsables de las enfermedades contagiosas. En otros casos, se trata de nuevos dispositivos diseñados para la determinación cuantitativa de sustancias especificas, como el sulfimetro, los varios modelos de clorómetros de Gay-Lussac (uno "antiguo" de sulfato de índigo y otro "moderno" de ácido arsenioso) o el Bertolímetro para el blanqueo. Por último, se recogfan en el catálogo dispositivos experimentales disenados para la extracción de determinadas sustancias, como el "diagómetro de Rombeau" para analizar los aceites o el «aparato de Darcet" para extraer la gelatina de los huesos.

La primera diferencia que podemos observar en estos «aparatos» respecto a los "efectos" $y$ "utensilios" tradicionales es el hecho de que se trate de equipos experimentales especialmente diseñados para realizar operaciones específicas. En algunos casos, se trataba de montajes formados por recipientes y utensilios de metal, vidrio o porcelana, similares a los que se acumulaban en los armarios y los estantes del viejo laboratorio, pero que, a diferencia de aquellos, formaban un "aparato" único utilizado para realizar una operación específica mediante la aplicación de una técnica concreta. En otros, eran dispositivos con diseños y graduaciones especiales, que los convertían en instrumentos de precisión difficilmente sustituibles o reproducibles. La distinción entre unos y otros puede reconocerse también en la documentación: los inventarios y las listas de adquisiciones recogen esta dis- 
tinción entre los nuevos «aparatos» y el resto de «efectos de porcelana, vidrio y cristaln, entre los que se encontraban los modelos y series completas de matraces, embudos, cubetas, morteros, probetas, retortas, sifones, tubos, vasos y frascos de diversos tamaños y formas, que fueron también renovados y ampliados.

No se han localizado todavía fuentes directas -cuadernos de estudiantes, ejercicios y cuestionarios, o guiones y esquemas de las clases escritos por los profesores- que informen sobre el uso concreto de estos «aparatos». Pero sí se pueden identificar diferencias importantes en el tipo de prácticas docentes para las que estos "aparatos" estaban destinados. Tanto en los inventarios como en los informes sobre las adquisiciones que deseaban realizar aparecen referencias a los usos de los instrumentos como herramientas didácticas. Los instrumentos y aparatos aparecen destinados a "demostrar", "probar" o "comprobar" determinado fenómeno o propiedad, o a ilustrar las técnicas propias de la "clase de obtención» de una determinada sustancia. En otros casos son simplemente identificados como "aparatos de cátedra». Resulta también interesante constatar que, para cada uno de estos instrumentos, se contaba y se solicitaba una sola pieza, en raras ocasiones dos. Todo ello hace pensar en un uso principalmente expositivo, en el que los «aparatos" eran empleados para realizar demostraciones ejecutadas por los profesores $\mathrm{o}$ ayudantes durante las clases y con las que se ilustraban y probaban las explicaciones y descripciones trasmitidas oralmente. Los «aparatos» de química se acercaban de este modo a la función desempeñada por las máquinas e instrumentos de física. Con la ayuda de estos equipos prefabricados, los alumnos podían visualizar los procesos de obtención, síntesis o análisis de sustancias químicas o las propiedades y comportamiento químico de sustancias, tal y como era explicadas por el profesor y descritas y representadas gráficamente en sus manuales de enseñanza.

En realidad, tales cambios no añaden diferencias sustanciales respecto a la situación descrita para los cursos impartidos por Villanova desde finales del siglo XVIII. También en aquel caso las demostraciones experimentales anunciadas en la prensa local tenían un fuerte carácter expositivo y su orden de presentación era también semejante al adoptado en los manuales de química utilizados. Aun siendo esto cierto, existe una diferencia importante en la concepción y diseńo de estos aparatos que pudo condicionar de manera sustancial el tipo de actitud y actividad frente a la enseńanza y el aprendizaje en la que tales objetos situaban a profesores y alumnos. Nos referimos a la posibilidad que aquellos sencillos y accesibles utensilios multiuso daban a los oyentes de los cursos de re- 
petir de forma individual e independiente los experimentos con ellos realizados, frente a las que ofrecían estos costosos y relativamente complejos «aparatos" prediseñados por fabricantes especializados y comprados por las instituciones de enseñanza como piezas con las que engrosar y completar sus colecciones. $\mathrm{Al}$ igual que ocurría con las máquinas e instrumentos de física, los fenómenos y experiencias químicas quedaban asociadas de manera indisoluble a un "aparato" específico, sin cuya presencia era imposible reproducir el proceso en cuestión. El uso de estos nuevos instrumentos prediseñados para la demostración de un tipo de fenómeno o procedimiento experimental concreto, dejaba fuera del horizonte de expectativas de los estudiantes la posibilidad de realizar por sí mismos las experiencias. Como había ocurrido antes con las máquinas de física, los aparatos de química se convertían a partir de ese momento en simples apoyos visuales de los experimentos explicados en el aula por el profesor. Resulta significativo que las colecciones "completas" de "cuerpos simples", de "productos químicos", de "principios orgánicos» y de "sustancias colorantes" aparezcan en los documentos de solicitud y compra junto a las colecciones de minerales destinadas a "demostrar los caracteres de estas sustancias", como si de un gabinete de mineralogía se tratara.

Estos cambios en el diseño de los instrumentos didácticos destinados a la enseñanza de la química son contemporáneos con importantes transformaciones tanto en la representación de las experiencias en los libros de texto como en la composición del público destinatario de tales obras. El desarrollo de las técnicas de impresión y de los modos de producción del libro transformaron el mundo editorial en el segundo tercio del siglo XIX e introdujeron importantes novedades materiales y formales en la producción de libros y, en particular, en la de libros de texto. Entre ellas figuraba la posibilidad de incorporar imágenes al cuerpo del texto y de dotar a estas de una alta calidad y definición. Los antiguos diseños esquemáticos reunidos en tablas al final del texto dieron paso a representaciones de escenas dotadas de un alto realismo, en las que los instrumentos podían ser integrados en los espacios y entornos materiales de un laboratorio y los fenómenos con ellos producidos eran representados con el máximo detalle. Se hizo también posible la reproducción de escenarios naturales e instalaciones industriales, imágenes desconocidas hasta entonces por buena parte del público lector. Las nuevas posibilidades iconográficas afectaron también al contenido y el estilo del texto escrito. Buena parte de la información sobre el diseño de los aparatos, su funcionamiento o las características de los fenómenos con ellos producidos fue transferida a la imagen. La antigua narración-receta dio paso a textos 
mucho más escuetos, carentes de información factual e instrumental y concentrados en la explicación e interpretación del proceso representado en la imagen. Con la incorporación de las ecuaciones estequiométricas, estas explicaciones fueron reducidas todavía más, llegando a ser una simple lectura guiada de lo representado de forma analítica en la fórmula y gráfica en los grabados $^{54}$.

Los libros de texto se poblaron así de multitud de diseños en los que eran representados modelos de los mismos instrumentos reunidos en las colecciones formadas por las instituciones docentes, llegando a la identificación entre contenido y estructura de gabinetes y libros de texto mencionada más arriba. A ello contribuyeron de forma decisiva los grandes fabricantes

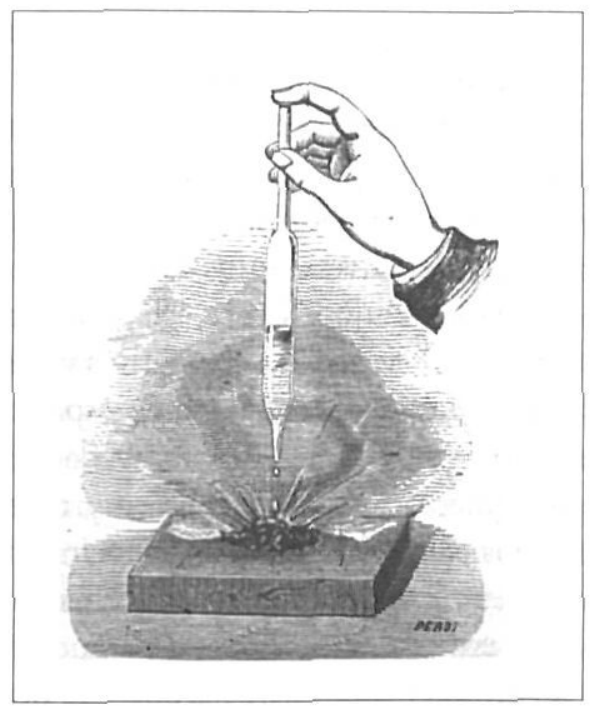

Figura 5

La explosión producida al verter ácido sulfúrico sobre materias combustibles, la forma de los cristales de alumbre o las instalaciones industriales para la extracción y concentración del ácido bórico podían ser visualizadas a través de los grabados incluidos en los libros de texto. de instrumentos, que vieron en los nuevos recursos iconográficos un excelente modo de publicitar sus modelos, como hasta entonces habían hecho a través de sus catálogos ilustrados. A medida que las ilustraciones de los manuales se estandarizaron y las colecciones de instrumentos se configuraban en los manuales y los gabinetes, también lo hacía el contenido de los cursos y las prácticas docentes.

Al tiempo que esto ocurría, la progresiva consolidación de los sistemas educativos y la incorporación de la química a los diferentes niveles y tipos de enseñanza estaba provocando una progresiva especialización de los estudiantes. La enseñanza de la química dejaba de practicarse en cursos públicos abiertos a un amplio abanico de

54 Sobre esta cuestión, v. Bensaude-Vincent, B.; García Belmar, A.; Bertomeu SÁNCHEZ, J.R., L'émergence d'une science des manuels..., op. cit. pág. 285. 
estudiantes, para comenzar a encasillarse en instituciones, espacios públicos y marcos normativos en los que los conocimientos impartidos eran regulados por programas, libros de texto y necesidades formativas muy concretas, $y$ donde los alumnos eran seleccionados por edad, necesidades formativas y destino profesional, recluidos en espacios en los que el acceso estaba vedado a cualquier otro tipo de público y registrados para acceder a unos conocimientos dentro de programas de formación bien estructurados. De estos «estudiantes profesionales", para los que, por otra parte, la enseñanza de esos mismos saberes era una de sus principales salidas profesionales, se esperaba únicamente que fueran capaces de reproducir las mismas explicaciones y demostraciones didácticas aprendidas durante sus estudios a través de las demostraciones y los manuales. Así lo reflejan las únicas referencias que aparecen en los textos normativos a las enseñanzas prácticas que debían adquirir los estudiantes de ciencias de las Facultades de Filosofía. En

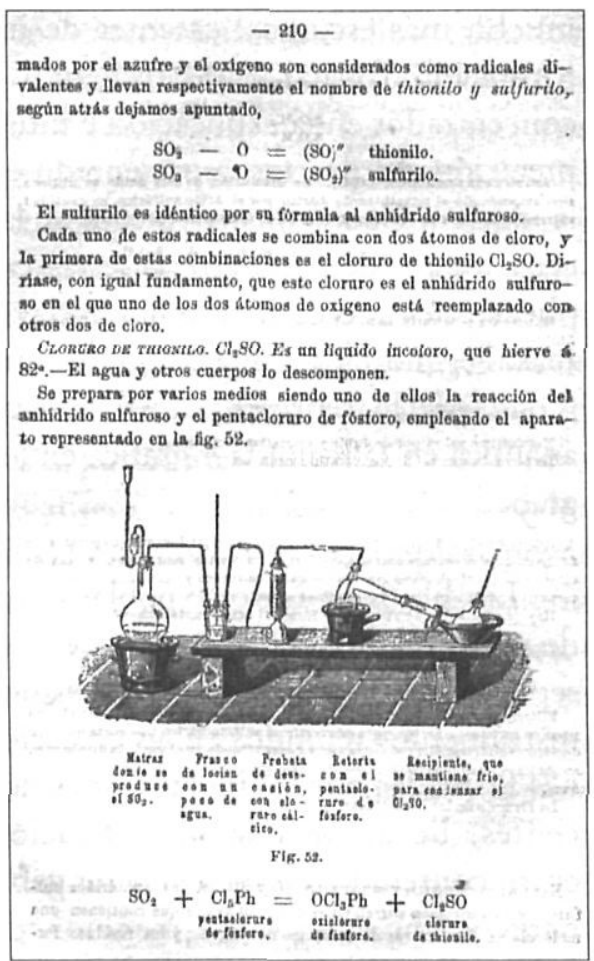

Figura 6

Descripción del proceso de preparación del cloruro de thionilo en el Compendio de las lecciones de quimica general impartidas por José Ramón de Luanco en la

Universidad de Barcelona

(3a ed., Barcelona, 1893, pág. 210)

las pruebas para la obtención del grado de licenciado, se pedía a los que optaran a la licenciatura de ciencias que tanto en la exposición del tema elegido entre los doscientos del programa como en las repuestas a las preguntas de los "censores", se debería «invertir el tiempo necesario para los experimentos y demostraciones con las máquinas y aparatos necesarios al efecto». El ciclo se cerraba de este modo alrededor de unas experiencias e instrumentos tipo, que los estudiantes aprendían a manipular para llegar a ser capaces de reproducir posteriormente, como profesores, frente a otros estudiantes ${ }^{55}$.

55 Algo más exigentes, en tiempo aunque no en contenido, eran las pruebas para optar a una cátedra. Según el artículo 209 del Reglamento, «si la lección exigiere experimentos, preparaciones 
La creación de las Facultades de ciencias en 1857 y las nuevas remesas de instrumentos científicos adquiridos a raíz de esta nueva reforma institucional vino a consolidar esta tendencia anunciada ya en la compra de instrumentos de 1846. La Ley de Instrucción Pública promulgada en 1857 bajo el ministerio de Claudio Moyano supuso un cambio importante en la situación institucional de la enseñanza de las ciencias en el contexto de las Universidades. La antigua Facultad de Filosofía, que hasta entonces había reunido los estudios científicos y literarios, fue dividida en dos facultades independientes, las de filosofía y letras y las de ciencias exactas, fisicas y naturales, que formaron parte de las facultades mayores separándose de la enseñanza secundaria. Los centros de enseñanza secundaria impartían los cursos conducentes al título de bachiller en artes necesarios para acceder a las facultades de filosofía y letras o de ciencias, donde podían obtenerse los grados de bachiller, licenciado y doctor. Tal y como subrayaba el Reglamento y otras disposiciones adicionales que desarrollaron la Ley Moyano, las nuevas facultades de ciencias debían cumplir un doble objetivo: formar a los futuros profesores de la enseñanza secundaria y de las propias facultades de ciencias y letras y ofrecer los estudios de preparación para el resto de las facultades:

La Facultad de Filosofía y Letras y la de Ciencias Exactas, Físicas y Naturales, tienen dos fines que deben consultarse al determinar los estudios que han de atribuirseles. Sirven para formar profesores que las enseñen dignamente y para que en ellas adquieran la preparación necesaria los alumnos de aquellas carreras que exigen otros preliminares además de la segunda enseñanza ${ }^{56}$.

o disecciones anatómicas, se concederá al opositor el tiempo que los jueces estimen necesario para estas operaciones, no pasando de veinte y cuatro horas. En seguida se le incomunicará y se le suministrarán aparatos, instrumentos, sustancias, cadáveres y cuantos objetos fueren precisos con los libros que pidiere, y también cama y alimentos, según lo exija el tiempo que haya de estar recluso. Asimismo se le permitirá tener consigo uno o dos alumnos de los primeros años para que hagan de ayudantes o mozos que le sirvan; procurándose por todos los medios posibles que la incomunicación sea completa. Llegada la hora señalada, dará su lección, y se le harán objeciones en la forma prevenidam.

56 Programas generales de estudios, Madrid, 1858, p.25 (Citado en MORENO GonZALEZ, Una ciencia en cuarentena... op. cit., pág. 353). 
El grado de bachiller en ciencias se alcanzaba tras tres años de estudios en los que debían seguirse los cursos de álgebra y de física experimental el primero; geometría, trigonometría y química el segundo; e historia natural y ejercicios gráficos el tercero. Los grados de licenciado y doctor en ciencias podían alcanzarse en una de las tres secciones establecidas: exactas, químicas y naturales. $\mathrm{Al}$ igual que otras muchas facultades de ciencias, la de Valencia sólo fue habilitada para otorgar el grado de bachiller, reservándose la concesión de los grados superiores a la facultad de ciencias de la Universidad Central de Madrid. Esto limitó severamente la función de estas facultades de distrito que se redujo a la de proporcionar los estudios de preparación para los estudios de medicina y farmacia, así como para todas las escuelas técnicas especiales y superiores. Por otra parte, dado que la Universidad Central de Madrid fue la única autorizada para otorgar el grado de doctor, ésta se perfiló como la responsable de la formación de los profesores de Universidad mientras que las facultades de ciencias de distrito quedaban encargadas de la formación de los profesores de los institutos de segunda enseñanza, a los que ahora se exigía el grado de bachiller. Este fue, por tanto, el destino profesional que se abría ante los 51 bachilleres en ciencias que se graduaron en la Facultad de ciencias de Valencia entre 1857 y 1868.

Fue para estas enseñanzas de preparación a los estudios de medicina y farmacia o para las escuelas técnicas superiores y para ese reducido grupo de futuros bachilleres en ciencias para los que se acometió una nueva renovación del material de los gabinetes y laboratorios de la Facultad de Ciencias, así como las obras para la adecuación de nuevos espacios que permitieran ofrecer una enseñanza adecuada. En noviembre de 1855, los responsables de la universidad enviaban al gobierno un informe de los trabajos que debían acometerse para acondicionar los espacios dedicados a la historia natural, la física y la química en el edificio de la Universidad de Valencia:

... el gabinete de historia natural, ha quedado ya completo faltándole solo el aula necesaria, que dejó de arreglarse anteriormente para cuando pudieran adecuarse los gabinetes de fisica y de química, cuyos objetos y maquinas estaban hacinados en unos mismos armarios y local con la única clasificación que esta permita. Mas ahora puede obtenerse un aula para las tres secciones, circular y con una chimenea para todas las operaciones químicas y demostraciones físicas de una forma perfecta según las necesidades de la enseñanza de los tres ramos. El gabinete de física tendrá un espacioso salón para las maquinas, otro el de química para sus objetos y el laboratorio nece- 
sario con muy poca armacion también separado, de modo que con esta reforma, necesaria pero aceptada ya tiempo ha pero dejada para atender a obras mas precisas, quedará ya esta universidad con las comodidades y decoro interior necesario y preciso. Falta pues reformar los balcones, hacer los bancos del aula en forma circular, construir la chimenea con las pizarras para cada sección reformar los armarios y construir otros para el nuevo salón, canalizar el gas y el agua de las fuentes, porque las cañerías pasan ahora por delante de las puertas del edificio y pintarlo todo hasta quedar con la debida armonía ${ }^{57}$.

Aunque la documentación disponible muestra que las obras fueron finalmente realizadas, no disponemos de planos que permitan visualizar los cambios precisos introducidos con esta reestructuración ${ }^{58}$. Podemos sin embargo identificar los espacios creados a través de planos posteriores, realizados en la década de 1880 , con motivo de algunas obras realizadas sobre la fachada (Figura 7). En ellos podemos visualizar las estancias descritas en el informe de 1855 y comprobar cómo los espacios solicitados y finalmente ejecutados respondían a un diseño muy similar al que Villanova imaginó a finales del siglo XVIII para su laboratorio de química y a los que el propio Motserrat i Ruitort venía solicitando desde hacía casi veinte años. El centro de toda la actividad docente seguía siendo el aula en forma de anfiteatro en la que los auditores se acomodaban en bancos dispuestos en forma circular alrededor de una mesa central y dotada de las instalaciones necesarias - chimenea y canalizaciones de aguas y gas - para la realización de las demostraciones químicas y físicas. Colindantes y comunicadas al aula, varias estancias, destinadas a almacenar las «máquinas" de física y los «objetos» de química y un laboratorio de química donde preparar las demostraciones que luego se mostrarían en el aula principal. Conocemos a grandes rasgos el tipo de "material fijo» con el que se dotó el gabinete y laboratorio de química, situados en las estancias marcadas con el número 5 en el plano de la figura 7 . Mientras el gabinete contaba con un solo armario y una mesa de trabajo, el laboratorio

${ }^{57}$ Expediente para la publicación y subasta de las obras que deben hacerse para el complemento de los gabinetes de física, química, e historia natural de esta universidad literaria, con arreglo a la R. Orden de 19 de enero de 1856. (AUV, 270/1).

58 Obras en los gabinetes de física, química e historia natural de la universidad de valencia. Arquitecto Juan Fornés, 1855-56. (AUV, 270/1). 
estaba dotado de un grupo de armarios supletorios para reactivos e instrumentos y una "mesa de tapa de mármol» y un "puente de mármol» para la preparación de las experiencias ${ }^{59}$. Por último, en los nuevos locales habilitados para las cátedras de física y química, aparecen por primera vez estancias donde alojar a los dos preparadores con los que por entonces contaban los catedráticos responsables de estas materias.

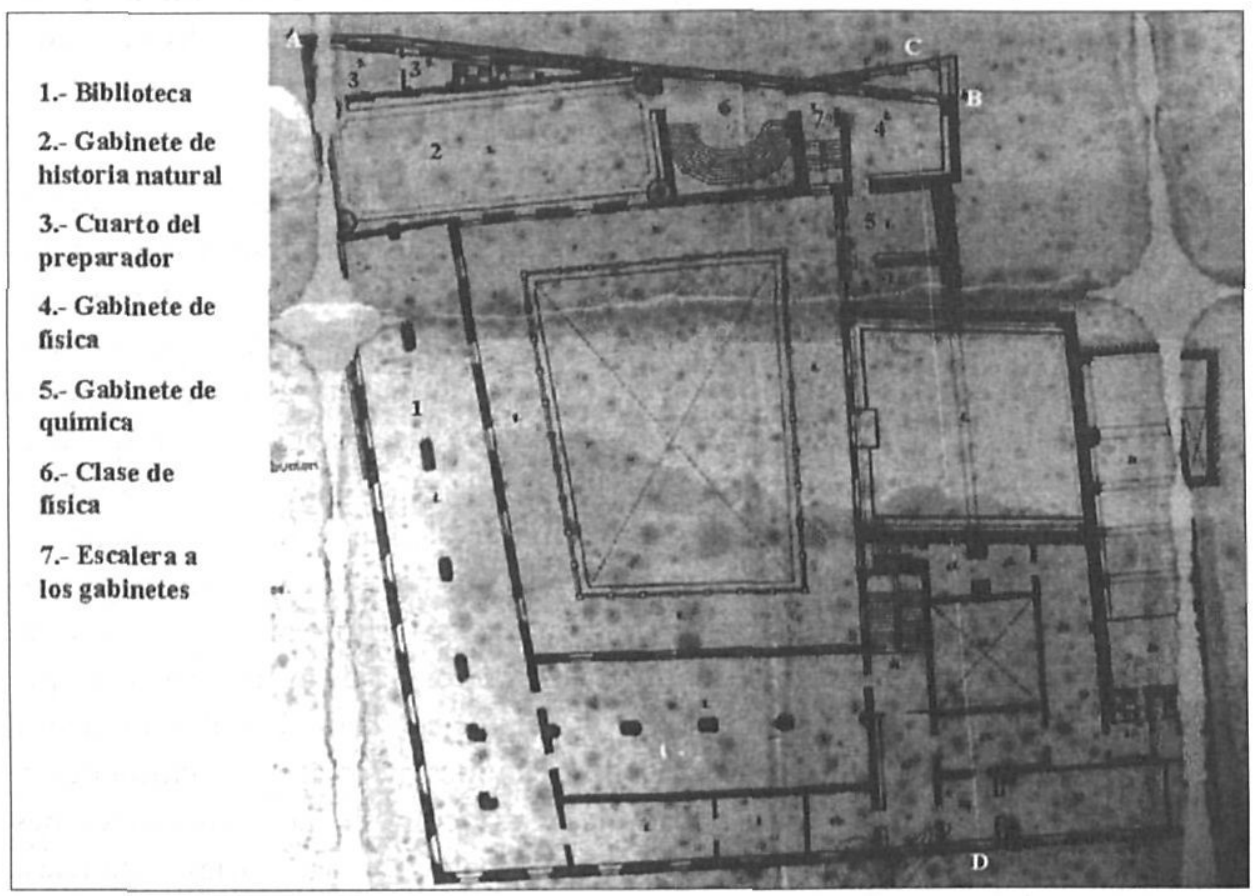

Figura 7

Plano de la primera planta del edificio de la Universidad de Valencia y sección CD en la que se pueden observar las armariadas de los gabinetes y laboratorio de física y de química, según el proyecto elaborado por Antoni Martorell en 1886. (Archivo de la Universidad de Valencia, Planero)

En lo referente a la nueva compra de instrumental, la documentación contable de la Universidad de Valencia analizada por Sánchez Satiró muestra la presencia de una fuerte inversión en material científico durante los años 1860-61 (211.340 reales de vellón) y 1863-63 (112.230 reales de vellón), lo que supuso

${ }^{59}$ Inventario y justiprecio... de 1864. 
en este segundo caso el $60 \%$ de los gastos totales de la Facultad ${ }^{60}$. Una parte importante del presupuesto ordinario y extraordinario fueron dedicados a la organización del Jardín Botánico y del Museo de Historia Natural. Los gabinetes de física y de química, aunque en cantidades menores, también recibieron fondos extraordinarios por valor de 18.015 y 14.750 reales de vellón, respectivamente, que se sumaban a los 4.400 y 11.840 de los presupuestos ordinarios respectivos. Estos fondos permitieron a José M. Guillén y José Montserrat, catedráticos de física y de química respectivamente, comprar nuevos materiales para sus gabinetes, que no habían podido ser renovados desde la compra de 1847-1848.

El Inventario y justiprecio del material existente en el Gabinete y Laboratorio de la Cátedra de Quimica General de la Facultad de Ciencias de la Universidad de Valencia, realizado en diciembre de 1864 nos permite hacer una primera valoración del volumen de material disponible después de esta segunda compra y de sus principales características. El grueso de instrumental del laboratorio fue ordenado según el material de fabricación, siguiendo una vieja tradición que ya hemos visto en otros casos anteriores. Lo formaban un total de casi 3000 "efectos" y "utensilios» de vidrio y cristal, cerámica y alfarería, metal y madera valorados en 24.930 reales de vellón. Entre ellos se acumulaban las mismas series completas de recipientes de todo tipo y herramientas para su manipulación, que hemos venido observando en los inventarios anteriores y que, como hemos señalado, conformaban esa parte estable del laboratorio químico. Junto a este material tradicional y versátil, susceptible de ser empleado en operaciones de muy diverso tipo, el inventario recogía una sección independiente de «aparatos de laboratorion, formada por 135 objetos y valorada en 22.484 reales de vellón, lo que suponía un gasto similar al presupuestado para todo el resto del material de laboratorio. Vuelven a aparecer aquí algunos de los equipos experimentales adquiridos en 1848, a los que se unían una larga lista de nuevos "aparatos» e instrumentos de análisis cuantitativo.

La nueva remesa de aparatos y máquinas venía a consolidar esa tendencia señalada en el apartado anterior, en la que los «efectos" y "utensilios" del laboratorio tradicional eran progresivamente sustituidos por sofisticados apara-

60 SÁnChez SATIRo, Cientifics $i$ professionals. La facultat de Ciències de València, València, Univ. de Valencia, 1998. 
- Alambique de Salleron.

- Alcalímetro de Descroizilles

- Alcalímetro de Gay-Lussac.

- Alcoómetro centesimal de Gay-Lussac.

- Aniquilador del fuego de Phillips.

- Aparato de Dumas para la síntesis del agua.

- Aparato de Dumas y Boussingault para el análisis del aire.

- Aparato de Gay-Lussac y Thenard para análisis de sustancias orgánicas.

- Aparato de lixiviación de Robiquet.

- Aparato de Marsh con gasómetro y surtidor con llave.

- Aparato de Marsh modificado por la Academia.

- Aparato de Mitscherlich para reconocer el fósforo.

- Aparato fumigatorio portátil de Guyton de Morveau.

- Aparato para descomponer el agua por el hierro.

- Aparato para la preparación de las aguas gaseosas por Briet.

- Aparato para la preparación de los cloruros de azufre.

- Aparato para la preparación del ácido fluorhldrico.

- Aparato para la preparación del ácido fosfórico anhidro.

- Aparato para la preparación del ácido sulfúrico.

- Aparato para la preparación del ozono por el azufre.

- Aparato para la preparación del ozono por la pila.

- Aparato para llenar de hidrógeno los globos aerostáticos.

- Apreciador de Robine para el análisis de harinas.

- Areómetro para ácido, de Cartier, para éter, para leche, para orina, para lejias, para nitrato de plata y de plata para los jarabes.

- Balanza de laboratorio de dos platos.

- Balanza de Roverbal.

- Balanza pequefia para pesar granos con estribo de metal.

- Balanza de análisis sensible a 1/2 miligramo, cuchillas sobre planos de ágata, platos y serie del gramo en platino y caja de caoba, id. con caja pintada de negro y serie de pesos.

- Bafio Maŕa de cobre con discos de recambio.

- Bomba de Gay-Lussac para los aparatos de análisis orgánico.

- Caja de plomo para grabar el vidrio por el ácido fluorhidrico.

- Campana con llave para los gases y graduadas.

- Clorómetro de Gay-Lussac.

- Diagómetro de Rousseau para analizar los aceites.

- Daguerrotipo normal con objetivo de retrato y de vistas con todos los accesorios para fotograffa; id. $1 / 4$ en placa; id. de 30 por 40 con objetivo de vistas.

- Eudiómetro compuesto de Volta.

- Eudiómetro de cristal con armadura de hierro para el mercurio.

- Eudiómetro de gas nitroso con medida.

- Eudiómetro de Gay-Lussac con válvula de latón.

- Fragua portátil con fuelle de doble viento y hornillo.

- Gasómetro de cobre barnizado de 100 litros con cubeta superior y llaves.

- Lámpara de aceite de Berzelius para el soplete.

- Lámpara de Berzelius para alcohol de doble corriente.

- Lampara de Davy o de seguridad.

- Lámpara de esmaltar con dos candilejas de latón y mesa de nogal.

- Lámpara de esponja de platino.

- Lámpara electrica de Gay-Lussac.

- Laboratorio portátil de Guyton de Morveau.

- Probeta de Regnier para ensayar la pólvora.

- Sifón de metal con llave para aguas gasesosas.

- Soplete de Barruel con caja y vejiga; id. de Berzelius con punta de platino; id. ordinario.

- Sulfidrómetro Dupasquier.

- Termómetro de mercurio.

- Válvula de agua o soplete para adaptar a los gasómetros.

- Vejigas preparadas para gases.

Tabla 1.

Lista de objetos incluidos en la sección de "aparatos de laboratorio" del Inventario y justiprecio del material existente en el Gabinete y Laboratorio de la Cátedra de Quimica General de la Facultad de Ciencias de la Universidad de Valencia (Archivo de la Unviersidad de Valencia, C306-9).

tos diseñados para la realización de operaciones específicas de análisis cualitativo y cuantitativo o de síntesis de sustancias específicas. La tabla adjunta da una idea de la especificidad y complejidad de esta nueva remesa de aparatos y 
máquinas que transformaron el aspecto del instrumental del laboratorio de química y de las prácticas asociadas a su utilización en la enseñanza. Del mismo modo, la disposición de los espacios destinados a la enseñanza muestra un uso diferenciado de éstos, en los que los gabinetes y laboratorios aparecen como estancias reservadas al profesor y sus ayudantes, destinadas principalmente a la preparación de las clases impartidas en las aulas o anfiteatros. Así se deduce también de lo recogido en el Proyecto de reglamento interior de la Facultad de ciencias, redactado en noviembre de 1867 por José Monserrat, en el que se establecían las normas de uso de "los gabinetes de mineralogía, zoología, anatomía comparada, el laboratorio de disección, el Jardín Botánico, el gabinete de física y el gabinete y laboratorio de química general". Los catedráticos correspondientes eran los responsables de estos espacios y los encargados de "formar los catálogos oportunos adoptando la clasificación que creyeran conveniente». Ellos y sus ayudantes eran los únicos autorizados a utilizar estos espacios y los materiales allí conservados. Además de mantener a punto todas las máquinas, el ayudante debía "preparar cuantas sustancias se necesiten en el laboratorio y en las clases", así como "asistir al profesor en la parte experimental» de todas las lecciones. La principal función de estas dependencias y materiales era, según el proyecto de reglamento, "conservar las colecciones necesarias para la enseńanza y promover por todos los medios las investigaciones científicas y prácticas».

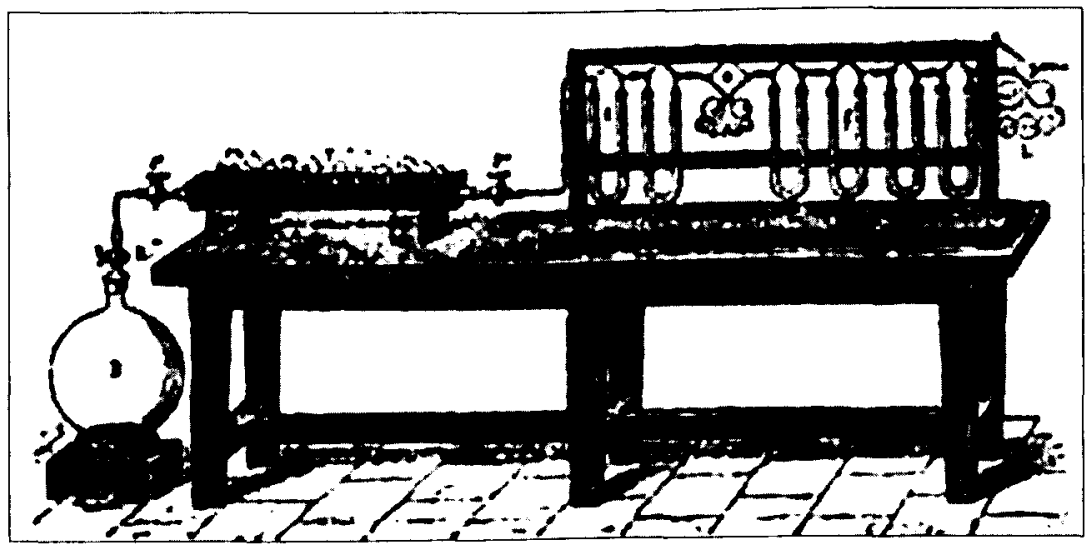

Figura 8

Aparato de Dumas y Boussingault para el análisis del aire según una representación incluida en el Compendio de las lecciones de química general de José Ramón de Luanco (32 ed., Barcelona, 1893) 
El proyecto de reglamento, que sancionaba de este modo un uso de estos espacios limitado a la conservación de las colecciones y a las investigaciones que los profesores debían realizar junto a sus ayudantes, abría sin embargo un pequeño hueco para los alumnos. José Montserrat proponía en este documento la puesta en marcha de un sistema de "papeletas" que los alumnos recibirían como acreditación y como forma de control del acceso tanto a los laboratorios como al jardín botánico. El uso de estas papeletas para los alumnos se trataba en el mismo punto en el que se establecían las normas para el acceso de "extranjeros y transeúntes" interesados en visitar estas dependencias de la Universidad, lo que indica que su objetivo era, más bien, realizar un control sobre visitas guiadas al laboratorio, y no tanto el fomentar la frecuentación asidua necesaria para la realización de trabajos prácticos. A pesar de ello, supone un primer paso que anuncia las importantes transformaciones de las prácticas docentes que se ensayarán durante el sexenio revolucionario.

\section{El laboratorio como espacio de enseñanza}

Las reformas institucionales emprendidas tras la Revolución de 1868 mermaron parcialmente el papel reservado a la Universidad Central de Madrid, abriendo nuevas posibilidades para el resto de Universidades espańolas. Además, la reforma de las enseñanzas técnicas otorgó nuevas atribuciones a las Facultades de Ciencias. Además de ser la facultad encargada de ofrecer los estudios preparatorios para las carreras de medicina y farmacia, las Facultades de Ciencias se convirtieron también en las facultades preparatorias de los estudios de ingeniería y las responsables de impartir los cursos teóricos de estas carreras profesionales. Es en este nuevo contexto en el que hay que entender otra novedad importante: la creación de la licenciatura de ciencias exactas en la Facultad de Valencia, en 1868, y con ello la posibilidad de impartir los cursos y otorgar los grados de licenciatura y doctorado. Entre 1867 y 1871 la Facultad de ciencias de Valencia pudo conceder los tres títulos, aunque en la práctica solo acabó concediendo títulos de bachiller y doctor (22 en total), pero ninguno de licenciado ${ }^{61}$.

De nuevo, la reforma institucional fue acompanada de presupuestos extraordinarios para la compra de nuevos materiales para el laboratorio y gabinete

${ }^{61}$ SANCHez Santiro, Cientifics i professionals..., op. cit., págs. 295-300. 
de química y el gabinete de física. En esta ocasión, la compra se hizo a través del "Laboratorio químico farmacéutico" del Dr. Francisco Valero Mira, que suministró numerosos instrumentos tomando como referencia los que figuraban en los catálogos de los fabricantes franceses Lerebours y Salleron. Los inventarios realizados en 1873 recogían una colección que para entonces contaba ya con 485 «máquinas» de física y 5512 «objetos» de química "comprados la mayor parte de Paris" ${ }^{62}$. El gabinete de física, albergaba 71 "máquinas" de mecánica, 26 de hidrostática, 23 de hidrodinámica, 6 para el estudio de las acciones moleculares, 27 de neumática, 31 de "Meteorologia», 16 de acústica, 40 sobre el calórico, 56 de óptica, 14 de magnetismo, 32 de electricidad, 24 de galvanismo, 44 de electromagnetismo, 33 de matemáticas, 6 de geografia y 5 de fotograffa. Por su parte, el laboratorio de química había también aumentado sus efectivos en casi todos los grupos de objetos y su valor estimado ascendía ahora a 30.000 pesetas. Los «aparatos e instrumentos" sumaban ahora un total de 199 piezas, los «efectos» de vidrio, metal, porcelana y madera eran ahora 3815 , la colección de productos químicos contaba con 1258 muestras y 67 la de minerales, mientras que la colección de "grandes cuadros representando fabricaciones químicas" contaba con 53 láminas. En apenas una década, el gabinete de física y el laboratorio de química habían aumentado sus efectivos en casi un $40 \%$.

La novedad más importante no se encontraba, sin embargo, en la mejora de la dotación de los laboratorios y materiales, sino en los nuevos usos didácticos que se pretendió dar a estos materiales y espacios. En 1869, el claustro de la Facultad de Ciencias decidía abrir a los estudiantes los gabinetes de física y química, el museo de Historia natural y el jardín botánico, a fin de que los estudiantes pudieran «adquirir la práctica necesaria en el reconocimiento y uso de los aparatos y colecciones de objetos científicos que por el sistema adoptado en la enseñanza solo observan durante la demostración de las lecciones oralesm. Para ello se estableció un "reglamento de clases prácticas de la Facultad de Ciencias" que fue publicado en la prensa local ${ }^{63}$. El preámbulo de dicho documento reunía algunos de los principios básicos de los nuevos métodos de enseñanza de las ciencias:

${ }^{62}$ Breve noticia de los medios materiales de instrucción de esta Universidad, Catedra de fisica, 1873, AUV, C226-4.

${ }^{63}$ Reglamento de clases prácticas de la Facultad de Ciencias, Diario mercantil de Valencia, 24 de febrero de 1869, p. 2 (Citado en SANCHEZ SÁNTIRO, Cientifics i professionals..., op. cit., pág. 40). 
A fin de que los alumnos públicos y privados de la facultad de ciencias, puedan adquirir la práctica necesaria en el reconocimiento y uso de los aparatos y colecciones de objetos científicos que por el sistema adoptado en la enseñanza sólo observan durante la demostración de las lecciones orales, ha determinado el claustro de esta facultad establecer un nuevo método de instrucción que servirá de complemento de la enseńanza técnica, permitiendo á los discípulos la entrada en los diferentes gabinetes y en el jardín para que se ejerciten en trabajos de clasificación, manejo de máquinas ó en manipulaciones químicas. ${ }^{64}$

Además de los alumnos oficiales y libres de la Facultad de ciencias, los gabinetes y los laboratorios se abrían a «toda clase de persona que se propongan algún trabajo en las ciencias físicas o naturales». De acuerdo con lo que indican los registros de asistencia esta disposición fue seguida ampliamente ${ }^{65}$. Al gabinete de física y al laboratorio de química, que permanecieron abiertos los miércoles y los sábados de tres y media a cinco y media de la tarde, acudió un amplio número de estudiantes que a menudo superaba la matrícula de la facultad de ciencias, reuniendo a muchos de los que seguían los cursos preparatorios a otras carreras. La única limitación contemplada era la impuesta por el espacio, los recursos disponibles y la disponibilidad de los profesores y ayudantes que eran los responsables de "dirigir los trabajos, resolver las dudas que ocurran, y también para dar ocupación a los que asistan sin determinado objeto". Las limitaciones impuestas por los recursos disponibles se hacían especialmente importantes en el caso de las "manipulaciones y análisis químicos" ya que, como indicaba el reglamento, "pueden exigir el uso de sustancias de bastante precio $\delta$ en cantidad considerable» por lo que se advertía que "el laboratorio dará únicamente los reactivos y utensilios de que puedan disponer según la escasez de sus recursos".

El impulso alcanzado durante los primeros años del sexenio revolucionario pronto comenzó a atenuarse. La supresión de las escuelas de industria y agricultura en 1870 puso en cuestión la permanencia de la licenciatura de ciencias exactas, que desapareció en 1871 . Por otra parte, la supresión del título

${ }^{64} I d$.

${ }^{65}$ Nota de los alumnos que asistieron a los ejercicios prácticos de la Facultad de Ciencias, AUV, caja 438 (Citado en SÁNCHEZ SANTIRÓ, Cientifics i professionals..., op. cit., pág. 41 ). 
de bachiller en ciencias en 1870 supuso un serio revés: la facultad de Valencia, al igual que el resto y con la excepción de Madrid y Barcelona, dejó de expedir título alguno, convirtiéndose en meras escuelas de preparación a los estudios de medicina y farmacia, situación en la que permanecerán durante todo el último tercio del siglo XIX. Hasta 1895, la Facultad de Ciencias de Valencia no volvió a otorgar ningún otro grado universitario, perdiendo con ello una de sus principales fuentes de ingresos, también mermadas por el continuo descenso en el número de alumnos matriculados. Baste señalar que durante todo este periodo, la dotación para gastos de material no superó las 1500 pesetas anuales, con las que debían cubrirse todos los gastos de reparaciones y obras, incluidas las del Jardín botánico. Esta penuria económica motivó numerosas protestas por parte de los profesores que denunciaban la imposibilidad de mantener una enseñanza práctica mínima. De hecho, el último curso en el que se registraron trabajos prácticos por parte de los alumnos fue el de 1875 a $1876^{66}$.

El estado de crisis de las facultades de ciencias alcanzó su punto culminante cuando en virtud del real decreto de julio de 1892 se suprimieron todas ellas, a excepción de las de la Central de Madrid y la de Barcelona. La actividad docente de las facultades de provincias quedaba de nuevo reducida a la de impartir los estudios preparatorios a las carreras de medicina y farmacia. Esta situación finalizó apenas tres años más tarde cuando las facultades de ciencias fueron de nuevo reinstituidas, en unas condiciones que, al menos en el caso de la de Valencia, marcaron el inicio de una nueva época.

El real decreto de agosto de 1895 reinstituía la Facultad de Ciencias de Valencia, con la capacidad de impartir estudios y otorgar grados hasta el de licenciado, en la especialidad de ciencias fisicoquímicas. Esto significaba que la facultad impartiria todas las asignaturas comunes de las tres especialidades existentes - fisicomatemáticas, naturales y fisicoquímicas- además de las correspondientes a la licenciatura de fisicoquímicas. La reforma de García Alix de 1900 modificó las secciones de las facultades de ciencias al separar en secciones distintas la física y la química. Desde esta fecha, la Facultad de ciencias de Valencia fue habilitada para la concesión del grado de licenciado en ciencias, en la sección de químicas. 
El aumento del número y la especialización de las cátedras dotadas para hacer frente a los nuevos estudios, especialmente importante en las materias de química, tuvo como consecuencia inmediata una ampliación del profesorado en todas sus categorías, lo que contribuyó a la renovación iniciada ya desde la década de los años ochenta con la jubilación o muerte de los titulares de las cátedras de física y química, Guillén y Montserrat. A las dos cátedras tradicionales se sumaron en 1895 las nuevas cátedras correspondientes a los cursos de la sección de fisicoquímicas, primero, y química, después. Junto a sus titulares, las antiguas y nuevas cátedras contaron con profesores auxiliares y ayudantes de prácticas, que engrosaron el personal docente. Fue en este grupo donde se concentró además el mayor número de personas procedentes de la Junta de Ampliación de Estudios, en cuyos laboratorios habían recibido parte de su formación. Este fue un factor importante en el desarrollo de la actividad investigadora dentro de la Facultad de Ciencias de Valencia ${ }^{67}$.

La mejora de la posición institucional de la Facultad de Ciencias de Valencia y la llegada del nuevo profesorado no fue acompañada de forma inmediata de una inversión extraordinaria que permitiera acometer las compras de materiales y la habilitación de los espacios necesarios para las nuevas enseñanzas. De hecho, durante bastantes años, las diferentes cátedras de química tuvieron que compartir el antiguo laboratorio de química general. En este espacio trabajaron juntos los alumnos de las asignaturas de química general, análisis químico, química inorgánica y química orgánica, con un instrumental que reunía objetos procedentes de las compras hechas desde los años cuarenta del siglo XIX con otros más recientes dentro de un estado general que Luis Bermejo calificó de "vergonzoso" en esos años.

La situación se hizo especialmente grave debido a la importancia que los nuevos planes de estudio concedían a las enseñanzas prácticas. Por primera vez, la asistencia a las clases prácticas se hizo obligatoria y fueron regulados los horarios y la frecuencia. La regularización de las clases prácticas fue acompañada del establecimiento de sistemas de evaluación. Los exámenes de prácticas fueron incluidos entre las pruebas para la obtención de los grados. Además del examen teórico, consistente en la elaboración de un tema del programa, se añadía un examen

67 Sobre la renovación del personal de la facultad de ciencias, ver SANCHEZ SANTIRo, Cientifics i professionals..., op. cit., capítulo 3, "Profesors de ciències (1857-1939)". 
práctico consistente en la preparación o análisis de un producto químico. Existen datos que confirman la existencia de este tipo de pruebas en la Universidad de Valencia desde el curso 1900-190168.

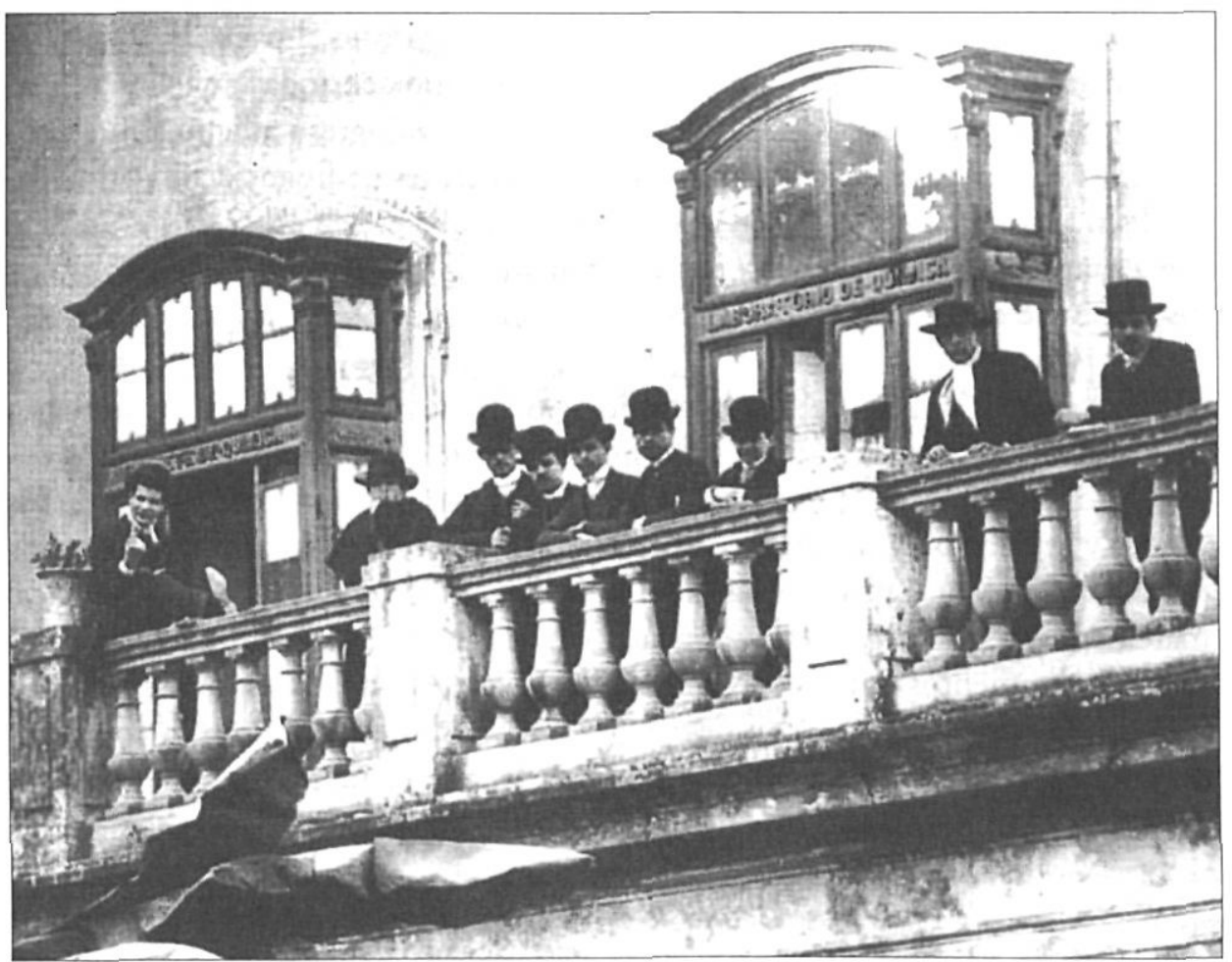

Figura 9

Alumnos concentrados ante las puertas del gabinete y laboratorio de química de la Universidad de Valencia e interior del laboratorio de química según imágenes de finales del siglo XIX (Archivo fotográfico J. Huguet).

La obligatoriedad de las clases prácticas agravó el problema de la falta de espacios y materiales para tales enseñanzas, hasta el punto de provocar la protesta de los profesores, que reclamaban una financiación especial con la que costear los gastos derivados de estas nuevas enseñanzas. Las Universidades seguían contando como únicos recursos los procedentes de los pagos de matrícula y de la

${ }^{68}$ Sanchez Santiró, Cientifics i professionals..., op. cit., pág. 52. 
concesión de grados, por lo que las partidas destinadas a la renovación de materiales siguieron siendo tan escasas como en las décadas anteriores. Las protestas de los profesores, que llegaron a amenazar con la suspensión de las clases prácticas, fueron contestadas por el gobierno con la introducción de nuevos tributos académicos para los alumnos. Desde 1900 fue obligatorio el pago de 10 pesetas en concepto de "derechos de prácticas de laboratorio" en todas aquellas asignaturas que contaran con este tipo de enseñanzas. Este ingreso adicional fue convirtiéndose a lo largo de los años en una de las fuentes de financiación principales de la Facultad, del $17^{\prime} 7 \%$ en $1909-10$ se pasó al $41 \%$ en $1929-30^{69}$. Un dato que es rambién un reflejo de la importancia que la enseñanza práctica cobró en los planes de estudio de las primeras décadas del siglo XX.

Este nuevo ingreso apenas permitió afrontar los gastos de mantenimiento más inmediatos y la compra algunos nuevos objetos. En efecto, las facturas correspondientes a estos años hacen referencia a gastos de mantenimiento de los locales y reparaciones de algunos instrumentos, como los realizados por el óptico valenciano Juan Lubat, titular de una casa de «instrumentos de óptica, física, matemáticas, electricidad, etcm. Apenas algunas facturas nos informan de la compra de instrumentos nuevos como es el caso de la usérie de 10 résonateurs de $\mathrm{Mr}$. Helmohltz" adquirida en abril de 1903 a la "Maison Spécial pour la construction des appareils de chimie et de physique» del fabricante parisino $\mathrm{G}$. Fontaine por 157,27 pesetas.

El Inventario general de los aparatos y utensilios del Laboratorio de quimica general de la Facultad de ciencias de la Universidad de Valencia elaborado en 1911 por Luis Bermejo, catedrático de química general, y el recientemente nombrado auxiliar numerario Casimiro López-Chávarri Marco da una buena medida del grado de deterioro que habían provocado en el material de física y química las tres décadas de abandono y penuria presupuestaria ${ }^{70}$. El número de "máquinas" almacenadas en el gabinete de física seguía siendo prácticamente el mismo que en 1873, salvo que ahora junto a muchas de ellas aparecían indicaciones sobre su estado "deteriorado", "antiguo" o simplemente "en desuson. Más grave había sido el deterioro y la pérdida de material de química. De los más de cinco mil objetos inventariados en 1873, en los 22 armarios del la-

${ }^{69}$ Id., 80-85.

${ }^{70}$ AUV, C306-2. 
boratorio de química tan solo quedaban 1797 "aparatos" $\mathrm{y}$ "efectos" $\mathrm{y}$ apenas un millar de "productos químicos usuales en las prácticas de laboratorio». La pérdida de materiales había afectado a todos los grupos, incluidos los menos susceptibles de ser dañados por el manejo, como la colección «dibujos de industrias químicas [...] colgados en las paredes del laboratorion de los que sólo quedaban cuarenta. $\mathrm{Al}$ igual que en el caso de las "máquinas" del gabinete de física, las indicaciones sobre el estado "deteriorado" o "en desuso" acompañan a buena parte de los instrumentos. Luis Bermejo describía algunas de las operaciones que podían hacerse con este material que debido a la falta de espacios adecuados se encontraba en gran parte «en depósito»:

Y si no fuera por la falta de espacio señalado, pues se juntan en la misma hora y en el mismo local alumnos de cuatro disciplinas, el bagaje y aparatos en depósito, es bueno para caracterizar especies y afirmar su pureza; para valorar la energía de algunas reacciones; seguir las caprichosas evoluciones de los rayos luminosos al través de la masa de los cuerpos, ora examinando brillantes espectros, ora apreciando la dislocación o el giro que aquellos sufren; examinar atentamente las variaciones de centésima e grado en los cambios térmicos de la congelación de disoluciones, en la ebullición de los líquidos... ${ }^{71}$

Cabe señalar, sin embargo, una novedad importante en las indicaciones al uso de los objetos recogidos en el inventario, sobre todo los del laboratorio de química, que reflejan una cierta consolidación de las clases prácticas e incluso de la participación activa de los alumnos, aun a pesar de las evidentes carencias materiales. Así, en los armarios 4 a 9 se guardaban un total de 1236 objetos calificados de "material movible para el servicio de prácticas" y formado por todo tipo de recipientes y utensilios de laboratorio generalmente en grandes cantidades, así como " 5 cajas de reactivos completas para las prácticas de los alumnos". A ellos se suma una "estantería abierta" en la que se guardaban un total de "200 frascos de boca ancha y estrecha con tapón esmerilado con diversos productos químicos usuales en las prácticas de laboratoriom. También aparecen registrados varias "cajas-neceser" guardadas en el armario 1 , entre las que se encontraban modelos didácticos de aquellos «aparatos» incorporados a la colección desde mediados de

${ }^{71}$ L. BERMEJO, "Establecimiento de tres nuevos laboratorios de química en la Universidad de Valencia", Anales de la Universidad de Valencia, 1, 1920-21, 328-330. 
siglo para la demostración de operaciones de análisis cuantitativo como alcalimetría y sulfidrometría, o para el análisis de sustancias orgánicas específicas como la leche o la orina.

Las décadas de los años veinte y treinta del siglo XX supusieron una importante renovación del instrumental cientifico de la Universidad de Valencia que fue bruscamente cortada por la Guerra Civil. La reforma de los estudios de 1922 fue acompañada además de una renovación de los laboratorios, que permitió actualizar los instrumentos y los espacios. Como ha señalado Sánchez Santiró, se produća por primera vez una cierta adaptación entre los planes de estudio, el material y las instalaciones ${ }^{72}$. Entre 1920 y 1923 se triplicó el número de laboratorios y se dotaron de nuevos materiales gracias, sobre todo, a los pagos de derechos de prácticas de los alumnos. Como muestra, baste señalar que, entre 1923 y 1924, se ingresaron 3.850 pesetas del Estado para material cientifico y 16.405 por derechos de prácticas de los alumnos. En un aula cedida por la Facultad de Filosoffa y letras y Derecho se instalaron los laboratorios y las cátedras de química orgánica y química inorgánica. El antiguo laboratorio quedó para las cátedras de química general y análisis químico y se proyectó un tercer espacio para albergar el embrión de un «laboratorio de investigaciones bioquímicas». Los laboratorios siguieron ampliándose durante los ańos 1920 hasta ocupar todo el terreno del claustro del edificio de la Nave que daba a la calle Salvá, cubriéndose con una estructura de vidrio y hierro.

El 12 de mayo de 1932 se inició un incendio en el laboratorio de química analítica en la primera planta y se extendió rápidamente hacia el Museo de Historia Natural, las aulas de ciencias y el observatorio astronómico. El incendio destruyó, entre otras instalaciones, el museo de historia natural, el observatorio y los laboratorios de análisis químico y de química general construidos en 1921 y 1922.

\section{Conclusiones}

En su contribución al volumen colectivo Abriendo las cajas negras, publicado con motivo de la exposición homónima organizada por la Universidad de Valencia, el historiador de la ciencia italiano Marco Beretta llamaba la atención

72 SANCHEZ Santiro, Cientifics i professionals..., op. cit., pág. 273. 
sobre la paradójica situación en la que están incurriendo buena parte de los estudios que, en los últimos años, han contribuido a reavivar el interés hacia los instrumentos científicos y la llamada "cultura material de la ciencia" ${ }^{73}$. Subraya este autor que, de manera sorprendente, aunque no inexplicable, los historiadores de la ciencia han preferido acercarse a los instrumentos científicos, no tanto a través de los ejemplares de éstos conservados en los museos, sino de representaciones gráficas y descripciones textuales. Y, en efecto, en la importante bibliografía sobre instrumentos científicos generada en los últimos años podemos encontrar detallados análisis de dibujos de instrumentos incluidos en cuadernos de laboratorio, de grabados en libros y artículos científicos o incluso de representaciones artísticas plasmadas por pintores en sus cuadros. Una amplia variedad de fuentes utilizadas para reconstruir los instrumentos científicos y sus usos, entre las que las fuentes materiales, los propios instrumentos objeto de estudio, suelen estar ausentes. La desaparición de instrumentos y colecciones es obviamente una causa que puede aducirse, pero como señala Beretta, ésta no es siempre cierta y ni mucho menos la más importante. Los historiadores de la ciencia siguen encontrándose más cómodos y seguros al fundamentar sus trabajos en fuentes documentales, impresas e iconográficas para cuyo análisis cuentan con una larga tradición historiográfica y sólidas herramientas metodológicas. Algo que no ocurre aparentemente con las fuentes materiales.

No es, sin embargo, la discusión sobre las causas de esa paradojica ausencia de los instrumentos en los estudios sobre los instrumentos cientificos la que nos interesa traer a colación en este último punto de conclusiones a nuestro trabajo. Nos gustaría, más bien, centrar la atención en las consecuencias que este hecho puede tener precisamente en las explicaciones y conclusiones que extraemos de estudios sobre el significado de objetos con los que, por no poder o por no saber, acabamos no enfrentándonos directamente. Cuando nos proponemos analizar el significado y el uso de los instrumentos científicos como herramientas de la investigación, como útiles didácticos o como recursos para la legitimación social de la ciencia, ¿̨hasta qué punto y en qué aspectos concretos nuestras conclusiones pueden estar distorsionadas, sesgadas o limitadas por el uso casi exclusivo de descripciones y representaciones de los instrumentos científicos, en lugar de los ins-

${ }^{73}$ M. BERETTA, "Definiendo los límites del patrimonio científico: arqueología, historiografía y habilidades prácticas”. En: J. R. BeRTOMEU SÁNCHEZ y A. Garcia BeLMAR (eds.), Abriendo las cajas negras... op. cit. págs. 83-99. 
trumentos mismos? ¿Qué puede decirnos un instrumento científico que no podamos saber a través de las descripciones o representaciones que sus usuarios hicieron de él?

Nuestro trabajo sobre la evolución de la colección de instrumentos científicos de la Universidad de Valencia y su significado en las prácticas de enseñanza e investigación desarrolladas en el marco de esta institución a lo largo del siglo XIX nos ha enfrentado de manera inevitable con este problema, puesto que, excepto posiblemente en un solo caso - el espejo reflector parabólico del fabricante francés Pixii ${ }^{74}$ - todos los instrumentos de este periodo han desaparecido (y no por causas fortuitas, como señalábamos al principio). A falta de los objetos, el estudio se ha basado fundamentalmente en el amplio rastro documental generado por la adquisición y mantenimiento de las colecciones. A través de los inventarios, registros y facturas, se ha podido conocer la composición de la colección en varios momentos de este proceso e identificar algunos cambios sustanciales en el tipo de instrumentos que la conformaron. Ha sido también posible comprobar que, frente a la fuerte continuidad en las características de los objetos reunidos en el gabinete de física y destinados a la enseńanza de la física experimental, el laboratorio de química experimentó un fuerte cambio desde las décadas centrales del siglo, debido a la incorporación de un grupo cada vez más importante de «aparatos", cuyo diseńo y uso difería sustancialmente del de los "útiles y recipientes» con los que se había enseñando la química hasta entonces.

En la colección de máquinas e instrumentos de física convivieron a lo largo de todo el periodo modelos de instrumentos que databan del siglo XVII con artefactos ópticos, eléctricos, magnéticos o mecánicos ideados apenas unos años antes e incorporados de manera inmediata al arsenal didáctico de los profesores de física. La coexistencia de objetos procedentes de épocas y contextos científicos tan diferentes fue posible, entre otras razones, por la similitud de los usos para los que habían sido diseñados. Se trataba de máquinas e instrumentos destinados a demostrar principios y leyes previamente enunciados por el profesor o el demostrador frente a un público de observadores. La máquina encarnaba el fenómeno producido con ella y éste se manifestaba en la enseñanza solamente a tra-

74 Espejo reflector parabólico, no de inventario: UV-9018. Puede verse en http://www.uv.es/=bertomeu/material/museo/instru/index.htm 
vés de esa máquina, de modo que ambos quedaban fuertemente ligados en la mente del observador. Los estudiantes entraban al gabinete de física a presenciar fenómenos singulares que sólo allí ocurrían, puesto que sólo allí se encontraban las máquinas que los producían.

Las experiencias mostradas y demostradas en el laboratorio de química no debieron de ser menos espectaculares, ni la participación en ese momento del público asistente mucho más activa. Pero, a diferencia de lo que ocurría con los fenómenos mostrados en el gabinete de física, las experiencias de química eran realizadas con utensilios y recipientes sencillos y polivalentes. Eran objetos de barro, vidrio o metal, que se combinaban de diferente modo para producir fenómenos diferentes y que, además, podían encontrarse en la más humilde de las boticas y adquirirse en las tiendas y talleres de artesanos de la ciudad. Todo ello abría la posibilidad real de que los asistentes más interesados repitieran por sí mismos tales experiencias, tal y como ilustra el recuerdo de Orfila de sus años mozos en Valencia. Esta circunstancia desapareció a partir de las compras de mediados del siglo XIX, cuando las nuevas remesas de materiales para el laboratorio de química comenzaron a incluir un grupo cada vez más nutrido de "aparatos", en cuyo nombre aparecía indicado el uso preciso para el que cada uno de ellos estaba destinado, tal y como era frecuente en las máquinas de física. Por otra parte, la complejidad del montaje experimental y de algunos de sus componentes hacía cada vez más remota la posibilidad de que los asistentes pudieran reproducir con sus propios medios y fuera del contexto del laboratorio las experiencias allí mostradas.

Estos cambios en los tipos de instrumentos y sus usos previstos fueron simultáneos con cambios en otros aspectos de la enseñanza que, en nuestra opinión, reforzaron los efectos antes señalados. En primer lugar, una importante modificación en la composición de los asistentes a los cursos. En las aulas, los laboratorios y los anfiteatros de ciencias de finales del siglo XVIII los estudiantes universitarios compartían aula con artesanos, médicos, cirujanos, boticarios y un variado público culto que resultaba atraído por la espectacularidad de las experiencias o por las promesas de utilidad de las nuevas ciencias experimentales. Esta situación cambió sustancialmente a lo largo del período analizado en este artículo. A medida que avanzaba el siglo XIX, el grupo de personas que asistían a las aulas de ciencias de la Universidad de Valencia se hizo cada vez más homogéneo. Se trataba, por lo general, de estudiantes inmersos en programas educativos bien definidos, tanto en sus contenidos como en sus propósitos formativos. 
Para ellos, se escribieron y publicaron numerosos libros de texto especialmente adaptados a sus necesidades formativas y a las nuevas condiciones materiales $\mathrm{e}$ institucionales de la enseñanza de las ciencias. Estos libros se convirtieron además en un objeto codiciado, no sólo por editores cada vez más especializados, sino por los fabricantes de instrumentos científicos, que vieron en las nuevas técnicas de impresión introducidas en la edición escolar desde los años centrales del siglo XIX un eficaz vehículo para dar a conocer sus modelos didácticos. El diseño de las máquinas y aparatos se estandardizó con una enorme rapidez en manos de un reducido grupo de fabricantes internacionales, ayudando a consolidar en toda Europa unas disciplinas escolares de contornos y contenidos cada vez más similares. La integración de imágenes cada vez más realistas y detalladas permitió trasladar a ellas una parte de la información transmitida antes a través de la palabra escrita. En el caso de la química, las largas y detalladas descripciones de las experiencias, casi recetas de cocina destinadas a ser repetidas, dieron paso a escuetos textos en los que se explicaba el proceso visualizado a través de la imagen y expresado de forma analítica a través de ecuaciones químicas.

La aspiración a que la enseñanza de las ciencias experimentales se hiciera fundamentalmente a través de la experiencia no se perdió con ello. Por el contrario, fue un argumento recurrente entre legisladores y profesionales de la enseñanza. Pero era una aspiración que debía de alcanzarse dentro de las limitaciones que las instituciones educativas eran capaces de ofrecer. La evolución de los espacios destinados a este tipo de enseñanza en la Universidad de Valencia muestra que los recursos disponibles no fueron ni suficientes ni adecuados. A pesar de las esperanzas expresadas alrededor de 1868, sólo muy a finales de siglo se emprendió la habilitación de espacios adecuados para que los laboratorios se abrieran a los estudiantes y se transformaran en espacios aptos también para la adquisición de saberes.

Las fuentes documentales, impresas e iconográficas utilizadas no se agotan con las preguntas planteadas hasta aquí. Existen otras muchas cuestiones acerca de las características, el significado y el uso de los instrumentos de ésta como de otras colecciones científicas que se pueden plantear y tratar de resolver a partir de los documentos asociados a su uso en la enseñanza o en la investigación. El análisis de los cursos manuscritos, los exámenes o los ejercicios realizados por estudiantes son fuentes de una extremada riqueza para conocer con detalle el tipo de prácticas docentes articuladas alrededor de los instrumentos cientificos. Por desgracia, también aquí la destrucción y la dispersión en archivos privados hace extremadamente difícil su recuperación. 
Pero, como señalábamos al principio, el principal obstáculo para seguir avanzando en una investigación de estas características es el hecho de que de estas ricas colecciones de instrumentos no hayan sobrevivido más que algunos vestigios. No poder examinar los objetos significa no poder entender con detalle cómo fueron manipulados, qué tipo de resultados era posible obtener con ellos, hasta qué punto pudieron servir de forma paralela para la enseñanza y para las investigaciones desarrolladas por profesores y ayudantes, o siquiera si los instrumentos fueron realmente manipulados o simplemente mostrados y descritos como si de un museo se tratara. Y, para estas preguntas, no sirven los modelos similares conservados en otras instituciones. Cuando de lo que se trata es de comprender cómo fueron evolucionando, en este caso, las prácticas asociadas a la enseñanza de las ciencias, cómo se fue pasando de forma gradual de unos modelos de enseñanza basados en la demostración en anfiteatros y aulas a otro centrado en la manipulación directa de los instrumentos por parte de los estudiantes en laboratorios de enseñanza, es necesario ir más allá de las grandes fechas y los cambios bruscos y espectaculares. Estos últimos pueden servir para la celebración de aniversarios de grandes descubrimientos o para la veneración de héroes científicos más o menos importantes pero difícilmente pueden ser el fundamento de estudios rigurosos de procesos lentos y complejos. Tampoco para el diseño de políticas culturales serias. La elaboración de inventarios, la restauración de las piezas y su estudio posterior requieren un trabajo especializado y de larga duración que, por lo general, resulta poco rentable para los que consideran el patrimonio histórico como una fuente de lucimiento político o de reconocimiento académico. Este desinterés de autoridades políticas y académicas es quizás el mayor problema que deben afrontar aquellos que, por el contrario, pretenden integrar a los instrumentos que han sobrevivido en el análisis riguroso de las prácticas científicas a lo largo de la historia. 